Linköping Studies in Science and Technology

Thesis No. 1676

\title{
Surface Integrity of Broached Inconel 718 and Influence of Thermal Exposure
}

\section{Zhe Chen}

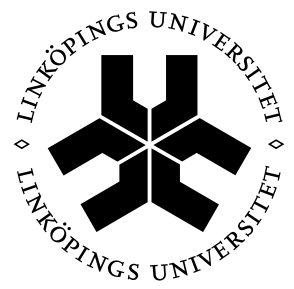

Linköping University

INSTITUTE OF TECHNOLOGY

\author{
LIU-TEK-LIC-2014:108
}

Division of Engineering Materials

Department of Management and Engineering

Linköping University, SE-581 83, Linköping, Sweden

http://www.liu.se

Linköping, September 2014 
Opponent: Adjunct Associate Professor Magnus Hörnqvist, Chalmers University, Göthenberg, Sweden.

Date: October 10, 2014

Room: ACAS, Linköping University

Thesis Cover: Chinese blue-and-white porcelain

Designed by Zhe Chen and Tianwei Xu

Printed by:

LiU-Tryck, Linköping, Sweden, 2014

ISBN: 978-91-7519-249-9

ISSN 0280-7971

Distributed by:

Division of EngineeringMaterials

Department of Management and Engineering

Linköping University

SE-581 83, Linköping, Sweden

(c) 2014 Zhe Chen

No part of this publication may be reproduced, stored in a retrieval system, or transmitted, in any form or by any means, without prior permission of the author 


\begin{abstract}
Inconel 718 is a nickel-based superalloy that is extensively used as a disc material in gas turbine engines. The service life of gas turbine discs is normally governed by the modes of material degradation and fatigue failure since they work mostly at high temperatures and are subjected to cyclic mechanical loadings. Fatigue failures often start with the initiation of cracks at the surface and the precise details of the failure process significantly depend on the surface conditions. In turbine disc production, one of the last manufacturing steps is to broach root fixings, commonly of fir-tree design, for blade mounting. It has always been a challenge when machining Inconel 718 due to its high strength retention at elevated temperatures, rapid work hardening, as well as low thermal conductivity. This usually leads to rapid tool wear, and consequently shorter tool life, and at the end to the deterioration of the surface integrity of the machined components.

The aim of this licentiate thesis is to increase our knowledge about the surface integrity, especially microstructure and residual stresses, of broached Inconel 718 and its stability under thermal exposure. This knowledge can later be used for analyzing the initiation and propagation of fatigue cracks in broached Inconel 718, particularly in the case of high temperature fatigue, thereby giving a better understanding of the failure mechanism of gas turbine discs from a fatigue point of view.

A broaching operation has been performed using similar cutting conditions as that used in turbo machinery industries for producing fir-tree root fixings. In addition, service damages were analyzed in a retired dis of Inconel 718. Surface defects, severe plastic deformation and generation of high tensile residual stresses have been found to be the main damages to the surface integrity caused by the broaching operation. The machining induced plastic deformation was found to accelerate the microstructural degradation beneath the broached surface when subjected to thermal exposure. The surface tensile residual stresses can be completely removed after short thermal exposure, the tensile layer in the sub-surface region, however, exhibited a high resistance to stress relief at high temperatures. The damage analysis on the retired disc indicated that presence of the highly deformed layer on the machined surface is negative for preventing the occurrence of fretting fatigue in turbine discs.
\end{abstract}





\section{Acknowledgements}

Siemens Industrial Turbomachinary AB has provided great supports for this research in material supplies and broaching manufacturing, for which it is greatly acknowledged.

I would like to express my sincere appreciation to my supervisor Ru Lin Peng. Thank you for providing the opportunity to let me come to Sweden to start my Ph. D study, and also for your support, supervision and encouragement since I started this project.

My co-supervisors, Johan Moverare and Sten Johansson are acknowledged for the constructive suggestions and inspiring discussions during this project. Also, many thanks to all my colleagues from Engineering Materials for creating a great and enjoyable working environment. The technical support from Annethe Billenius and technicians in the workshop is greatly appreciated. Agora Materiae and the Strategic Faculty Grant AFM (SFO-MAT-LIU\#2009-00971) are also acknowledged.

In addition, a collective acknowledgement goes out to my colleagues at Siemens Industrial Turbomachinary $\mathrm{AB}$ in Finspång, especially to Pajazit Avdovic, Fredrik Karlsson and David Gustafsson for their great contribution to this project. Jinming Zhou from Lund University is also acknowledged for his assistance in nano-indentation tests and the comprehensive discussions.

At the end, I want to thank my family and friends for always being there. My deepest gratitude leaves for my dear girlfriend Tianwei for her loving, accompanying and supporting.

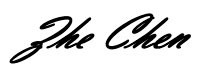

Linköping, August 2014 



\section{List of Papers}

In this thesis, the following papers have been included:

I. Z. Chen, R. Lin Peng, J. Moverare, P. Avdovic, J.M. Zhou, S. Johansson, Structural integrity of broached Inconel 718 subjected to thermal exposure. To be submitted to Journal of Materials Processing Technology.

II. Z. Chen, R. Lin Peng, P. Avdovic, J.M. Zhou, J. Moverare, F. Karlsson, S. Johansson, Effect of thermal exposure on microstructure and nano-hardness of broached Inconel 718. Presented at Eurosuperalloys 2014, Giens (France), 2014, published in the proceedings.

III. Z. Chen, R. Lin Peng, P. Avdovic, J. Moverare, F. Karlsson, J.M. Zhou, S. Johansson, Analysis of thermal effect on the residual stresses of broached Inconel 718. Advanced Materials Research, 966 (2014), 574-579.

IV. Z. Chen, J. Moverare, R. Lin Peng, S. Johansson, Damage analysis of a retired gas turbine disc. Accepted for presentation at Energy Materials 2014, Xi'an (China), 2014.

Papers not included in this thesis:

I. Z. Chen, R. Lin Peng, J.M. Zhou, J. Moverare, V. Bushlya, S. Johansson, ECCI and EBSD study of subsurface damages in high speed turning of Inconel 718 under different tools and machining parameters. Presented at ICF13, Beijing (China), 2014.

II. J.M. Zhou, V. Bushlya, R. Lin Peng, Z. Chen, S. Johansson, J.E. Stahla, Analysis of subsurface microstructure and residual stresses in machined Inconel 718 with PCBN and $\mathrm{Al}_{2} \mathrm{O}_{3}-\mathrm{SiC} w$ tools. Procedia CIRP, 13 (2014), 150-155.

III. R. Lin Peng, J. Moverare, P. Avdovic, A. Billenius, Z. Chen, Influence of vibration and heat treatment on residual stress of a machined $12 \%$ Cr-steel. Advanced Materials Research, 966 (2014), 609-614. 



\section{Contents}

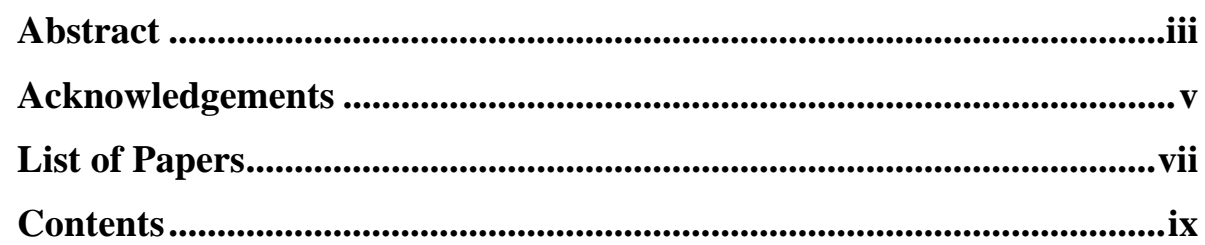

Part I Background \&Theory...................................................................1

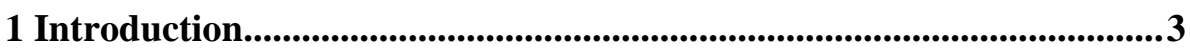

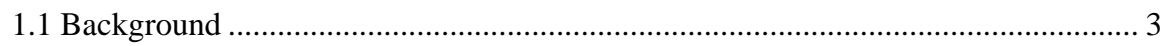

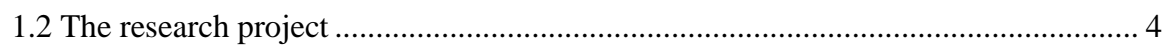

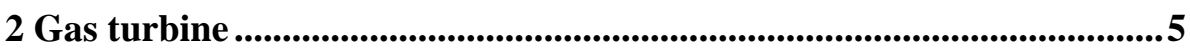

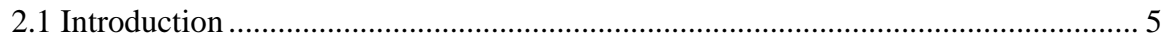

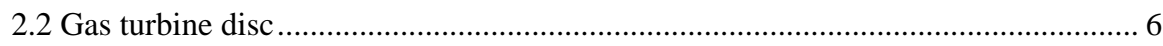

3 Component failures.........................................................................................9

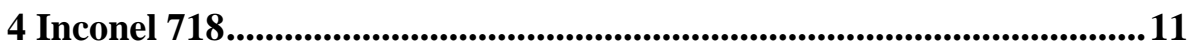

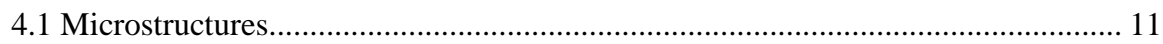

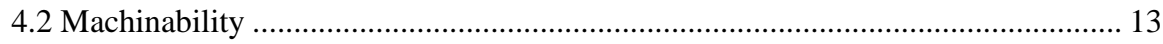

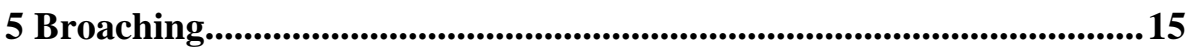

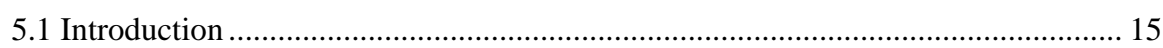

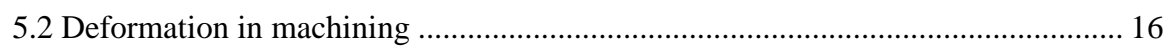

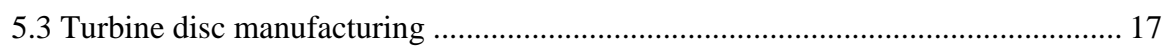

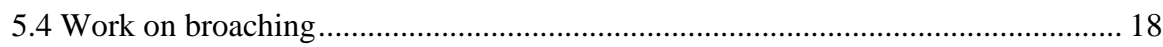


6 Surface integrity ...............................................................................................19

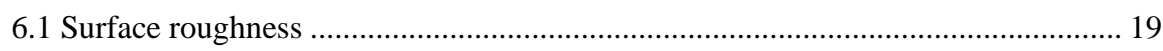

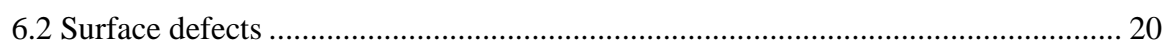

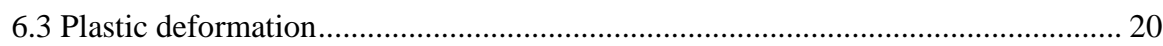

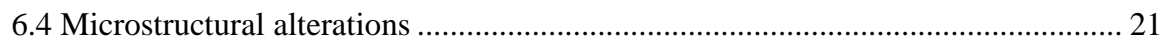

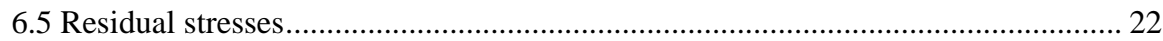

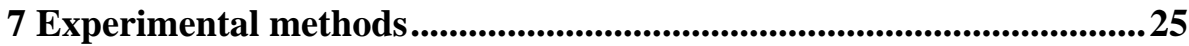

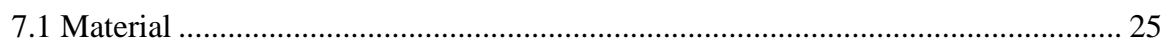

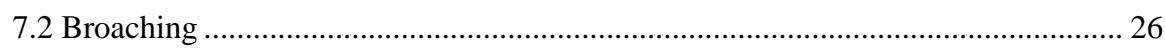

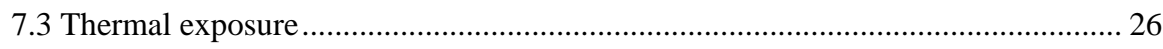

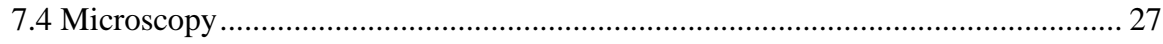

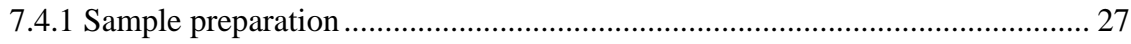

7.4.2 Scanning electron microscopy (SEM) ........................................................... 27

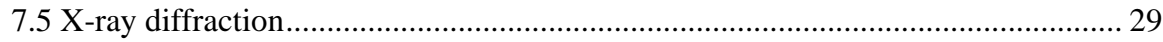

7.5.1 Residual stress measurement by diffraction ..................................................... 29

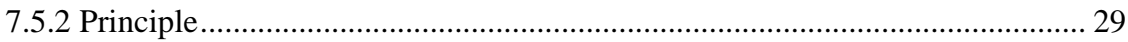

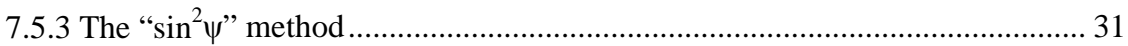

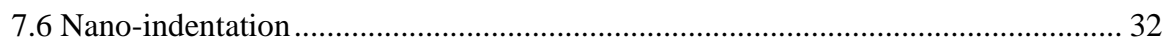

8 Summary of appended papers .............................................................33

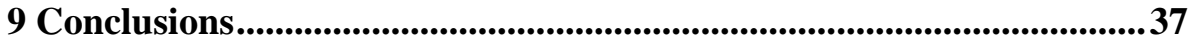

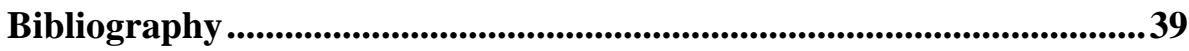

Part II Papers Included ...................................................................................45

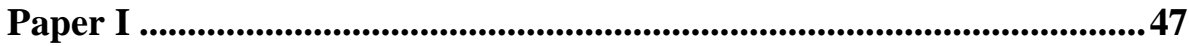

Paper II ............................................................................................................ 71

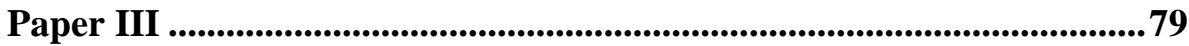

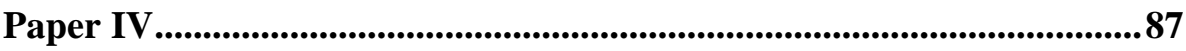




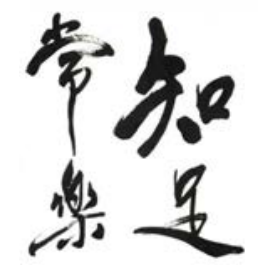

A contented mind is the greatest blessing a man can enjoy in this world.

老子(春秋战国思想家) Lao Tse (Chinese Philosopher in the Spring and Autumn Period) 



\section{Part I}

\section{Background \&Theory}





\section{1 \\ Introduction}

\subsection{Background}

Due to environmental issues and economic concerns, demands for increasing energy efficiency has led to many attentions focused on the development of more efficient power generation gas turbines. When designing a turbine engine, great emphasis is placed on the choice of the operating temperature since a higher generating efficiency can be achieved by operating the turbine at higher temperatures [1]. The increase in the operating temperature, however, puts forward higher requirements on the high temperature performance of the materials used in the hot parts of the engine. For these components, nickel based superalloys are often employed ascribe to their exhibition of capabilities of withstanding such aggressive service conditions.

Although with good high temperature performance, nickel based superalloys are used nowadays in gas turbine engines, the aggressive service condition still causes a multitude of material damages such as foreign object damage, erosion, corrosion/oxidation, creep, fatigue including high cycle fatigue, low cycle fatigue and thermal-mechanical fatigue, fracture and microstructural degradation in the components. Especially rotating parts in the turbine section, such as turbine discs and turbine blades which operate mostly near the temperature limit of the materials used, and are subjected to large centrifugal forces simultaneously have a potential risk for failure. The fatigue resistance of these critical components usually implies the endurance and reliability of a turbine engine. The turbine discs coupled with blades in a turbine engine, for example, are commonly life limited by the number of stop/start cycles to which they are subjected, rather than by the total hours of service since low cycle fatigue is imposed during the stop/start cycle in service which has been found to greatly contribute to disc failures [2]. 
Among the most important objectives in gas turbine design is therefore to enhance the fatigue strength and to prolong the fatigue life of such critical components. It has long been recognized that fatigue cracks generally originate from free surfaces [3] and that fatigue resistance is strongly dependent on the surface quality/integrity produced by machining. In turbo machinery industries, components have to be shaped to the designed profiles through various machining processes such as turning, broaching and milling etc. Nickel based superalloys are known to be difficult-to-cut materials, but most critical parts in gas turbines are made of these alloys. The surface integrity of machined nickel based superalloys therefore plays a key role in determining the fatigue resistance of the final parts, thereby affecting the endurance, reliability and safety of a gas turbine engine.

\subsection{The research project}

The first aim of this research project is to evaluate the surface integrity damages that could be induced during manufacturing of gas turbine discs, with a focus on the critical region where fatigue cracks normally initiate during the service, and additionally to increase our knowledge about the machining induced instability in the turbine disc, especially in terms of microstructure and residual stresses, when operating at high temperatures. This is also the focus of the work underlying this licentiate thesis.

To achieve the first aim of this project, a broaching operation was performed on a forged coupon of Inconel 718 using similar cutting conditions as that used in turbo machinery industries for producing fir-tree root fixings. The material that this project concerns is restricted to Inconel 718 as this nickel based superalloy is the most widely used disc material for gas turbines. The surface integrity of the broached Inconel 718 has been characterized, while the influence of thermal exposure on the microstructure and residual stresses beneath the broached surface has also been investigated. All results will be presented in this licentiate thesis.

As described previously, the fatigue properties that a machined component possesses are strongly associated with its surface integrity produced by machining. The second aim of this project therefore concerns the fatigue performance of broached Inconel 718, in particular under high temperature conditions. Great emphasis is to be placed on the correlation of the fatigue behavior with the surface integrity generated by broaching. The knowledge gained in this project can later be used for better understanding the failure mechanism in gas turbine discs from a fatigue point of view. 


\section{2}

\section{Gas turbine}

\subsection{Introduction}

A gas turbine is a type of internal combustion engine, mainly consisting of three main parts: the compressor, the combustor and the turbine. A Siemens gas turbine SGT-800 used for power generation is shown in Fig. 1. Fresh atmospheric air flows through the compressor that brings it to higher pressure as well as higher temperature by using compressor discs and blades. In the combustor, the compressed hot air is mixed with fuel, and ignited, generating a high-temperature flow. The high-temperature high-pressure gases then enter the turbine where they expand down to the exhaust pressure, and mechanical energy therefore is extracted by the turbine blades and discs which start to rotate. The rotating turbine disc is coupled to a shaft which is used to drive the compressor to keep the gas turbine operating and to drive other devices such as an electric generator that may be coupled to the shaft. The exhaust gases have either a high temperature or a high velocity, thus can be applied for different purposes.

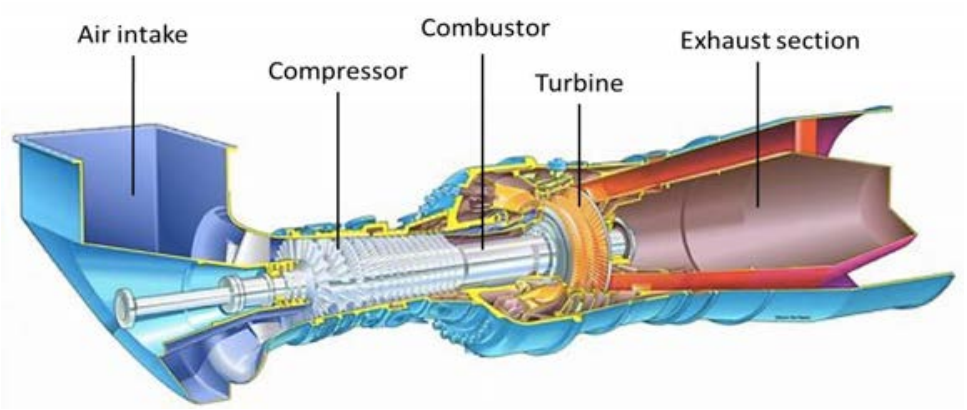

Fig. 1 SGT-800 gas turbine engine (Courtesy of Siemens Industrial Turbomachinary AB) 
When designing a gas turbine engine, the turbine entry temperature (TET): the temperature of the hot gases when they enter the turbine arrangement needs to be taken into consideration [1]. The efficiency of a gas turbine is greatly improved if the TET can be increased. This provides the technological impetus to enhance the temperature capability of the materials used in the combustor and the turbine section, and meanwhile to improve the material processing and the design of components.

\subsection{Gas turbine disc}

Turbine discs are the most massive and expensive rotating components in gas turbine engines. The main purpose of a turbine disc is to locate and retain the rotating turbine blades when the engine is operating. In the turbine stage, it usually comprises a set of discs, fastened onto a shaft, and on each disc, around 60-100 turbine blades are retained in the rim of the disc via root fixings, commonly of fir-tree design, as shown in Fig. 2. When the blades start to rotate, the disc and shaft also rotate. The fir-tree root fixings are designed to withstand the enormous centrifugal forces as the consequence of high rotational speeds. Compared with blades, turbine discs operate at relatively lower temperatures since they are not in the direct path when the hot gases from the combustor expanse trough the turbine, but the operating temperature in the rim section (near the gas flow path) still raises a challenge for the high-temperature resistance of the disc material.

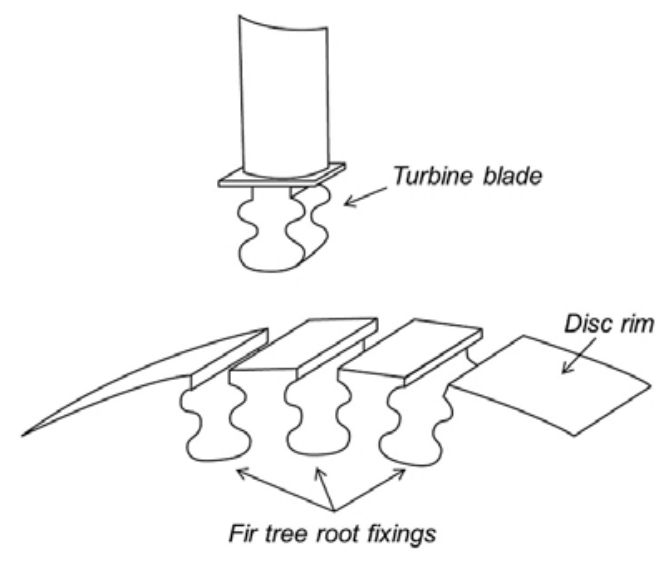

Fig.2 Fir-tree root fixing in the rim of a gas turbine disc

Turbine disc production usually starts with forged parts which have been pre-shaped by turning, milling and drilling operations, and one of the last features being manufactured are the fir-tree root fixings designed for blade mounting. Turbine discs represent a great 
challenge in turbo machinery industry due to the fact that they are complex components made of difficult-to-cut materials, and quality requirements are rigorous to ensure the highest level of safety. Therefore, advanced turbine discs not only rely on the development of disc materials for improved operating temperature, stringent control of machining tolerance and good surface/sub-surface quality that ensures high reliability and safety during its service is essential as well. 



\section{3}

\section{Component failures}

As mentioned in Chapter 2, a gas turbine, used for mechanical or electric power generation, is a complex system with numerous rotary and stationary parts. When the gas turbine is running, these parts experience aggressive operation conditions characterized by the following factors [4]:

- Severe operation environment (high temperature, especially for the parts in the combustor and the turbine, fuel and air contamination, solid particles, etc.);

- High mechanical loads (centrifugal forces, vibration and bending stresses, etc.);

- High thermal loads (due to thermal gradients, in particular for the alloys with low thermal conductivity).

Such aggressive operation conditions thereby result in a reduction in component service life, and even an unexpected failure of the gas turbine under the following damage mechanisms [2, 4-7]:

- Oxidation;

- Corrosion;

- Erosion;

- Creep;

- Fatigue;

- Foreign object damage.

For a gas turbine disc, basically there are three critical areas where attention should be focused: the dovetail-rim (fir-tree root fixings), the assembly holes and the hub zone, as shown in Fig. 3(a). The fir-tree root fixing where turbine blades are coupled with the disc as shown in Fig. 3(b) furthermore represents the most critical area from the point of view of creep and fatigue failures. Creep in a turbine disc normally takes place as a nature consequence that the disc rotates at high temperature and centrifugal stresses, whereas 
fatigue is related to either the much larger stress cycles imposed by starting and stopping or by over-speeding during the turbine operation (Low cycle fatigue), or the cyclic shear stress produced by friction due to the relative small oscillatory motion on two surfaces in intimate contact with each other (Fretting fatigue). The life of a turbine disc, for example, is commonly limited by the number of stop/start cycles to which it is subjected in service, rather than the operating hours. Meanwhile, the fretting fatigue that occurs at the contact surfaces of the disc and blade pressure face or the disc/shaft connection also endangers the durability and safety of the turbine disc. In order to prevent the occurrence of fretting fatigue failures, the US air force has to increase the frequency of maintenance, even to shorten the service life to ensure the safety [8].

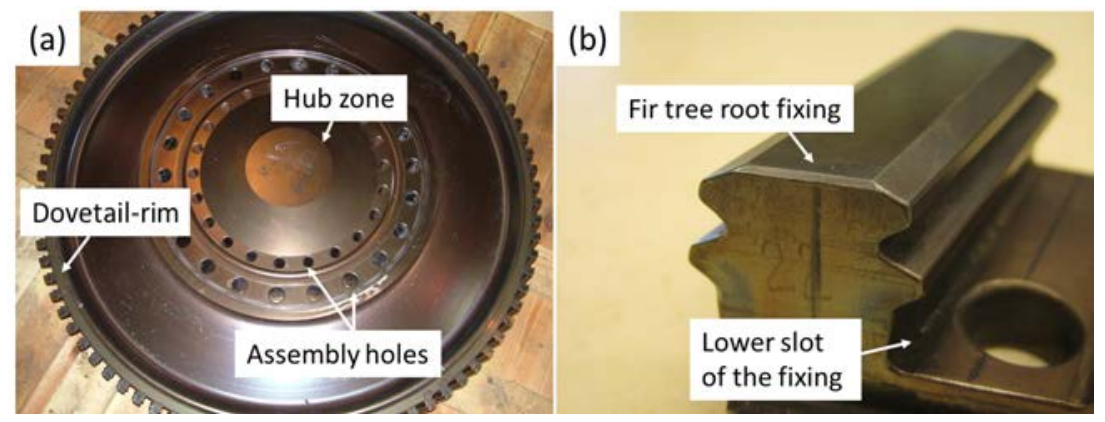

Fig. 3 (a) A retired gas turbine disc; (b) Fir tree root fixing for blade mounting

Turbine disc is a critical component in gas turbine engines. If a problem arises in the turbine disc, it will affect the whole engine function, even lead to catastrophic consequences. Fatigue failures have been found to be strongly dependent on the surface condition of the component being machined. In homogeneous materials, fatigue cracks normally initiate at the free surfaces [9], whereas in macroscopically inhomogeneous materials, such as surface treated metals by shot peening, cracks often start below the shot peened surface. In a failure case study performed by Hoeppner, fretting fatigue cracks initiated at the surface in the disc/shaft connection was found to be responsible for the final fracture of the turbine disc [10]. Also, another failure study conducted by Witek in a turbine disc indicated that the fatigue cracks originated from the surface at the corner of the lower fir-tree slot of a fixing eventually caused fatigue fracture, resulting in the separation of the entire fixing from the disc [2]. 


\section{4}

\section{Inconel 718}

Nickel based superalloys have been developed as the materials of choice for high temperature applications when resistance to loading under static, fatigue and creep conditions is required [11]. Inconel 718 is a nickel based superalloy that is extensively used in aerospace and power generation industries, in particular as the disc material in turbine engines.

\subsection{Microstructures}

The microstructure of Inconel 718 comprises an austenitic face centered cubic (FCC) matrix $\gamma$ as shown in Fig. 4(a), which is a nickel based solid solution containing $\mathrm{Cr}$, Fe etc. and some trace elements, $\mathrm{V}$ and $\mathrm{W}$, for instance. The primary strengthening phase is the precipitate gamma double prime $\gamma^{\prime \prime}$; it displays $\mathrm{D}_{22}$ body centered tetragonal (BCT) crystal structure and a composition which is approximately represented by $\mathrm{Ni}_{3} \mathrm{Nb}$. The nano-scaled $\gamma^{\prime \prime}$ precipitates are long disc-shaped as shown in Fig. 4(b) with the following orientation relationship to the matrix [12]:

$$
(001) \gamma^{\prime \prime}\left\|\{001\} \gamma ;<100>\gamma^{\prime \prime}\right\|<100>\gamma
$$

The strengthening mechanism in Inconel 718 is mainly attributed to the coherency strains between $\gamma^{\prime \prime}$ and the matrix [12]. The existence of $\gamma^{\prime}$ phase $\mathrm{Ni}_{3}(\mathrm{Al}, \mathrm{Ti})$, which has also been observed in Inconel 718 appearing as a fine dispersion of spherical particles, on the other also slightly contributes to the strength of the alloy [13].

In the overaged condition, Inconel 718 is susceptible to the formation of orthorhombic $\delta$ phase [14]. Nucleation of $\delta$ phase takes place mostly at grain boundaries and growth occurs at the expanse of $\gamma^{\prime \prime}$. The $\delta$ phase is incoherent with the matrix, and its presence at grain boundaries is believed to be detrimental to the fracture properties of Inconel 718 
[15], but it has also been reported to contribute to increased ductility and toughness of the alloy [16]. The formation of the extensive amounts of $\delta$ phase, however, gives rise to severe degradation of the mechanical properties of the alloy and is to be avoided. In addition, Inconel 718 usually contains $\mathrm{NbC}$ phase formed during solidification if the cooling rate is too fast [17]. The NbC phase appears as white large particles as shown in Fig. 4(c) and is relatively stable, with a result that it can still be found in homogenized microstructure. The initiation of fatigue cracks in Inconel 718 when the alloy is subjected to cyclic loads at high temperatures has been found to be strongly associated with the oxidation of $\mathrm{NbC}$ at the surface [18].
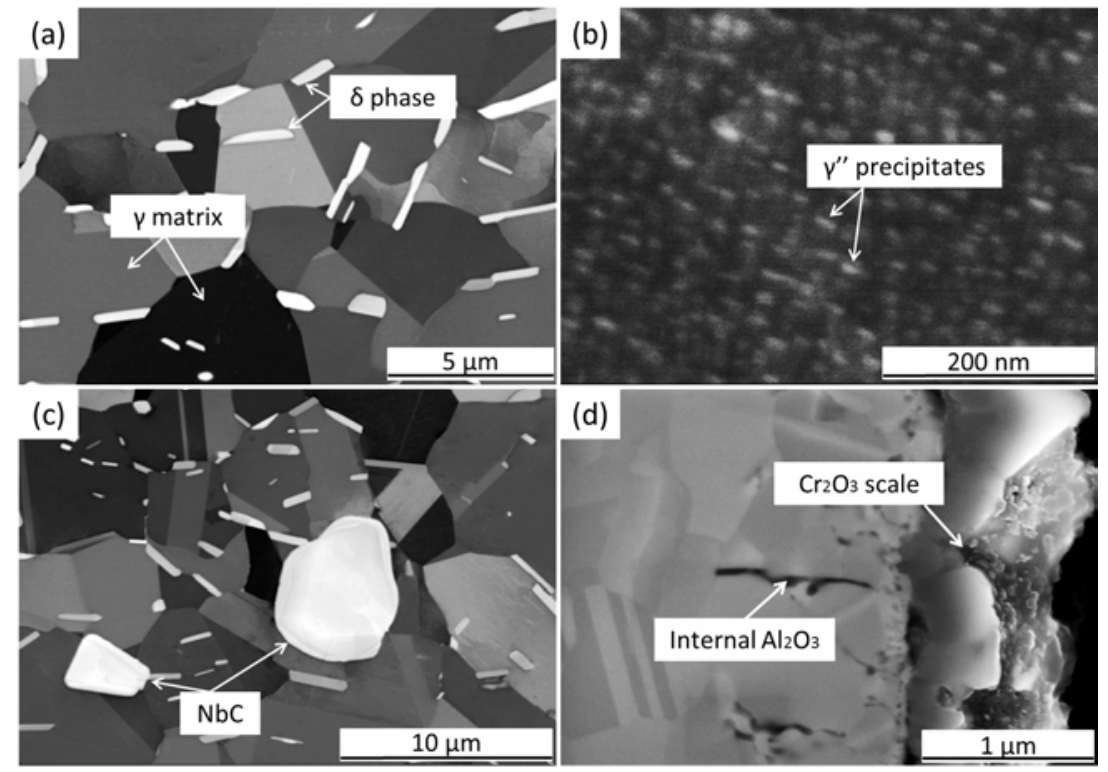

Fig. 4 Microstructure of Inconel 718: (a) $\gamma$ matrix with $\delta$ phase formed at grain boundaries; (b) the main strengthening phase nano-scaled $\gamma^{\prime \prime}$ precipitates with long disc shape; (c) $\mathrm{NbC}$ formed during solidification; (d) $\mathrm{Cr}_{2} \mathrm{O}_{3}$ scale formed after $3000 \mathrm{~h}$ thermal exposure at $650{ }^{\circ} \mathrm{C}$ in air

The heat treatment that is commonly utilized for Inconel 718 is composed of a solution annealing and a two-stage ageing [19]. The solution annealing is conducted at $925-1010$ ${ }^{\circ} \mathrm{C}$ slightly below the solvus of $\delta$ phase, then quenching in water. In such way, the temperature is high enough to dissolve alloying elements in the matrix, while the residual $\delta$ phase at grain boundaries can effectively limit grain growth. The homogenized alloy is subsequently aged at $720{ }^{\circ} \mathrm{C}$ for 8 hours in order to precipitate a high volume fraction of $\gamma^{\prime \prime}$ strengthening phase, then furnace cooled to a relatively lower temperature $620{ }^{\circ} \mathrm{C}$, held at $620{ }^{\circ} \mathrm{C}$ to continue the growth of the $\gamma^{\prime \prime}$ precipitates for another 8 hours, and finally air cooled to room temperature. 
The microstructure of Inconel 718 is stable and only degrades when exposed at a temperature higher than its aging temperature. Except for the transformation from $\gamma^{\prime \prime}$ to the $\delta$ phase as mentioned above, $\alpha-\mathrm{Cr}$ and sigma phases have also been found in the alloy after long-term thermal exposure at high temperatures above $650{ }^{\circ} \mathrm{C}$ [20]. These phases are formed as hard and brittle particles which are normally considered to be the natural sites of mechanical weakness. Inconel 718 has a good oxidation resistance since it contains a large concentration of $\mathrm{Cr}$, and the formation of the continuous $\mathrm{Cr}_{2} \mathrm{O}_{3}$ scale as shown in Fig. 4(d) can prevent the underlying material from further oxidation attack.

\subsection{Machinability}

Machinability is a term refers to the ease with which a component can be machined to the desired shape with acceptable surface finishing, dimension tolerance and surface/subsurface quality [21]. It has always been a challenge when machining Inconel 718 [22-26] because:

- The alloy can maintain high strength during machining due to its high temperature properties, with a result that high cutting forces are required;

- The poor thermal conductivity $\left(11-12 \mathrm{~W} / \mathrm{m}^{\circ} \mathrm{C}\right)$ of the alloy leads to high cutting temperature at the cutting zone

- Its tendency to rapid work hardening when subjected to high strain rate, causing further tool wear;

- Abrasive carbides included in the microstructure cause abrasive wear

- Diffusion wear frequently takes place as the consequence of the high chemical affinity of nickel based superalloys for many cutting tools

- Welding and adhesion of the workpiece that usually occurs during machining give rise to notching on the machined surface as well as changes of the tool rake face.

- Vibrations of the machine tool system because of the high cutting forces are detrimental to the surface quality.

The poor machinability normally generates two problems: short tool life and damages of surface integrity $[22,24]$. The quality of the machined surface plays a significant role on the surface sensitive properties, fatigue and corrosion resistance, for instance, which in turn determines the performance, reliability and service-life of the machined component. Extreme attention therefore should be paid to ensure the surface integrity when machining Inconel 718. 



\section{Broaching}

\subsection{Introduction}

Broaching is regarded as a machining method of choice when manufacturing components with complex features at tight dimensional specifications. It is also a highly productive machining process since the broach performs a sequence of roughing, semi-finishing and finishing cutting in one pass. There are two main types of broaching that are widely used nowadays: linear and rotary. Linear broaching is the more common process in which the broach moves linearly against a surface of the workpiece being manufactured. In rotary broaching, the broach is rotated and pressed into the workpiece to form an axis symmetric shape.

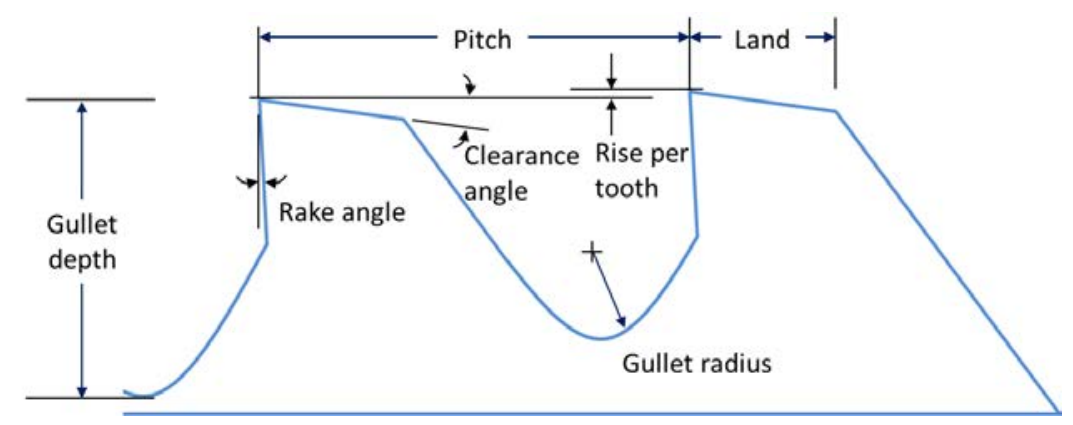

Fig. 5 the basic geometry of a broach tooth in the case of linear broaching

Fig. 5 shows the basic geometry of a broach that is used in linear broaching. The most critical characteristic of a broach is the rise per tooth (RPT) since a broach has many teeth and the height of the teeth increases over the length of the tool, the feed/depth of cut therefore, is built into the broach which is distinguished from all other machining 
processes. The RPT magnitude varies for each section of a broached from roughing until finishing. In addition, each broach is specially designed to cut just one profile, with the peripheral shape of the broach being the inverse of the final shape of the feature to be machined.

\subsection{Deformation in machining}

Broaching is a material removal process performed by mechanically forcing a cutting edge through a wokpiece. The machining process removes material from the workpiece by establishing a shear zone which is called the primary shear zone extending from the cutting edge to the work surface ahead of the cutting tool, as illustrated in Fig. 6 where a sharp wedge-shaped cutting tool removes materials with a preset depth by moving in the direction perpendicular to its cutting edge at a fixed speed. The angle that the shear plane makes with the surface generated is the shear angle $\phi$, which can be derived from the following expression [27]:

$\tan (\phi)=\frac{\frac{a_{0}}{a_{c}} \cos \alpha}{1-\frac{a_{0}}{a_{c}} \sin \alpha}$

Where $a_{0}$ is the un-deformed chip thickness, $a_{c}$ is the deformed chip thickness and $\alpha$ is the fixed rake angle.

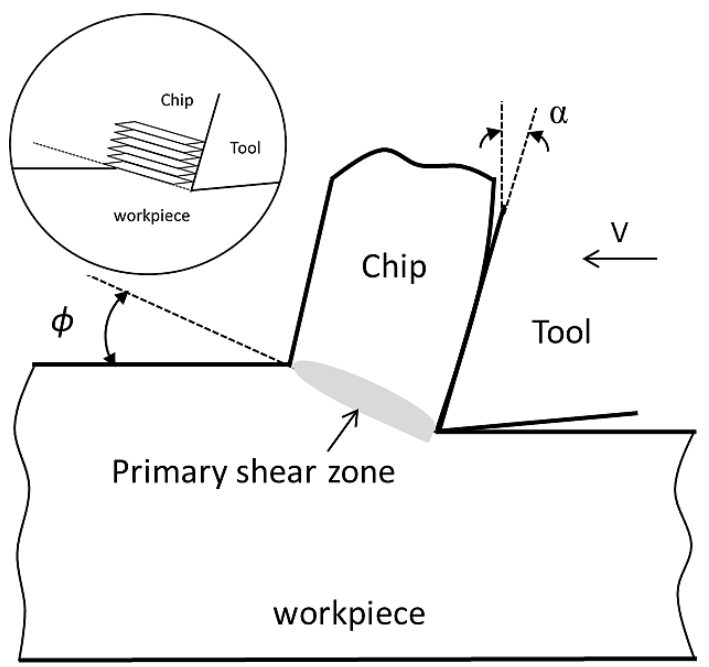

Fig. 6 Schematic illustration of shearing deformation in the orthogonal cutting process 
The deformation behavior in the primary shear zone is governed by the complex coupling between strain hardening and thermal softening. When strain hardening predominates, uniform plastic deformation takes place in the shear zone, resulting in continuous chip formation, whereas once the tendency of the material to harden with plastic deformation is overtaken by thermal softening effects due to the large local heat generation in the shear zone, localized shearing will then take place in a narrow band where the material has been softened [28]. The shear band can be further localized by the continued deformation heating, and ever higher strain rates and temperatures will be attained in this narrowing band. This shear localization is known as "catastrophic thermo-plastic shear" which is often observed when machining titanium alloys and nickel based superalloys owing to the high cutting forces required and their low thermal conductivity. During machining of these alloys, especially at high cutting speeds, the heat generated in the first primary shear zone due to the severe plastic work can not be dissipated, therefore forming an adiabatic zone [29] in which localized shear deformation occurs. Experimental observation and computerized modelling both have shown that when machining aged and forged Inconel 718 at relatively lower speeds, continuous chips are formed, whereas as cutting speeds increase, the chips produced become serrated with shear bands of highly localized deformation between the segments [30, 31].

\subsection{Turbine disc manufacturing}

In the turbo machinery industry, broaching has been successfully applied for decades. The most important applicaion is to machine the fir-tree root fixings on a gas turbine disc for blade mounting, and a schematic illustration showing that how the broaching is performed is presented in Fig. 7. The process starts by clamping the disc into the workholder which is mounted in the broaching machine. The elevator moves the broach above the work-holder, and then lowers the broach through the edge of the disc. In this case, the disc is held stationary, while the broach strikes linearly against it without any rotations. Once the broach goes through completely, the disc is removed from the machine and the broach is raised up back to its start position. The cutting material that is commonly used for broaching in industry is high speed steel (HSS), which provides high wear resistance and it is easily manufactured to the required teeth profiles. When broaching gas turbine discs made of difficult-to-cut materials such as Inconel 718, it limits cutting speeds in a range of $V_{C}=2-8 \mathrm{~m} / \mathrm{min}$ to get fine surface qualities, tight geometric tolerance and good sub-surface properties. 


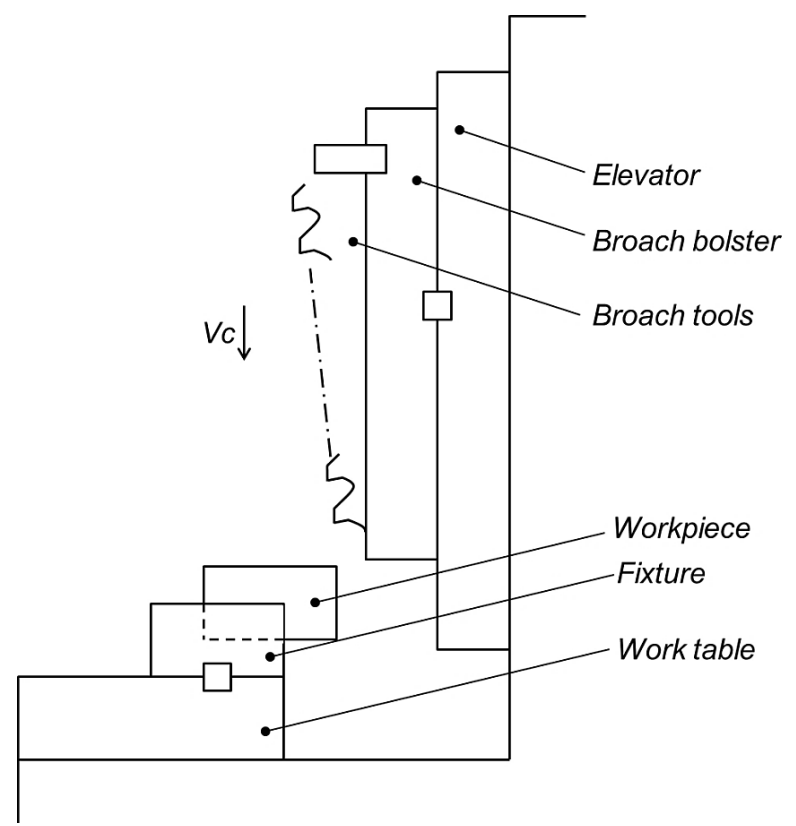

Fig. 7 Fir-tree root fixing broaching at the rim of a gas turbine disc

\subsection{Work on broaching}

Compared with other cutting processes, little work has been published on broaching even though it has great industrial importance. This is in part due to the expensive broaching equipment, both the machines and tools which is not affordable for academic researches. On the other hand, the manufacturers and tool designers are cautious to expose details of their valuable findings for competition reason. The influence of cutting variables on the surface integrity and broaching forces has been investigated by S.P. Mo et al when broaching heat resistant alloys [32]. F. Klocke et al studied the broaching of Inconel 718 with cemented carbide, and compared its performance with that produced by traditional high speed steels in terms of tool wear, cutting forces and surface integrity [33]. Some other issues of broaching were also reported in relation to tool condition monitoring [34], coolant effect on surface finish [35], dynamics of broaching [36] and accuracy [37]. 


\section{6}

\section{Surface integrity}

The concept of surface integrity was first defined in a technical sense by Field and Kahles as the inherent or enhanced condition of a surface produced by machining processes or other surface generation operations [38]. Typical surface/sub-surface alterations that might occur in a machined component include surface conditions (surface finish and other characteristic surface topological features), metallurgical state (microstructure, phase transformation, etc.) and mechanical state (micro-hardness, residual stresses, etc.). Field et al. [39] subsequently provided a detailed description with respect to the measuring methods that are available for surface integrity inspection. When critical structural components are machined with reliability and safety concerns, surface integrity is one of the most relevant parameters used for assessing the quality of the machined components.

\subsection{Surface roughness}

Surface roughness is perceived to be the primary indicator of the quality of a machined surface, and in most cases it is a technical requirement for manufacturers. Achieving a desired surface roughness is not only of great importance for the subsequent assembly, but also is pivotal in determining the service performance of the workpiece, in particular the fatigue strength and the fatigue life. It has been suggested that in the specimen with low surface roughness, polished surface, for instance, fatigue cracks usually initiate from persistent slip bands or at grain boundaries [40]. However, micro-notches induced by machining will lead to a localized plastic strain field when a load is applied due to the stress concentration. This zone of plasticity in which fatigue cracks are prone to initiate endangers the fatigue strength and the service life of the alloy. The effect of surface roughness on fatigue performance varies from one material to another, and it is also superposed with the effect of residual stresses and/or other factors [41]. 
When machining nickel based surperalloys such as Inconel 718 the high temperature generated has been found to lead to a rapid tool wear, and once the tools have worn, the surface roughness consequently was increased [42]. The built up edge as a typical type of tool wear that often occurs in machining of nickel based superalloys [25] can push the tool away from its original path to increase the roughness [43]. Also, the cutting parameters are very effective on the changes in surface roughness as well [44].

\subsection{Surface defects}

Many forms of surface defects have been found in machining processes [42, 45-49]. Feed marks, chip re-deposition to the surface and grain deformations are the ones in the largest scale on the machined surface, therefore considered to be the main surface defects. Also, most metal comprises more than one phase, plucking of hard particles and their redeposition on the surface give rise to surface cavities and subsequent smearing, dragging and even tearing defects on the next pass from the surface. Carbide cracking commonly occurs when machining materials containing carbide particles in the microstructure such as Inconel 718. The carbides are brittle, and unable to be deformed with the plasticized matrix, therefore prone to start cracking to release strains. This process could lead to surface cavities and cracks to be formed beneath the machined surface, therefore causing even further problems during the service. Surface defects can be reduced by selecting suitable cutting parameters based on the properties of the material to be machined [50, 51], but a complete elimination is not possible.

\subsection{Plastic deformation}

The main damage to the surface integrity of a machined component comes from the plastic deformation during the machining operation. The intensity of plastic deformation occurring in a machined component is determined by many factors such as cutting parameters, cutting speed, feed, depth of cut for instance, tool parameters including tool material, rake angle, geometry and wear, etc. and material properties (microstructure, grain size etc.). Among these factors, the tool wear has been shown to be the major reason that is responsible for severe plastic deformations [52]. When machining Inconel 718 at $V_{C}=32-56 \mathrm{~m} / \mathrm{min}, f=0.13-0.25 \mathrm{~mm} / \mathrm{rev}$, no significant plastic deformation was observed after 1 min of turning, whereas prolonged turning of 15 min resulted in severe plastic deformation beneath the machined surface. This is attributed to the localized heating as well as the higher stresses as the tool wears at the later stage of the turning. 
The main problem that plastic deformation is known to cause is work hardening of the surface and the sub-surface region of machined components as the response to the excessive plastic strains. An increase from the lower bulk hardness to a higher surface hardness has been found in many studies when machining titanium alloys and nickel based superalloys $[53,54]$. The increase in micro-hardness after machining becomes more severe for materials that exhibit high work-hardening tendency, such as nickel base superalloys. The work-hardened layer formed beneath the machined surface increases the difficulty for the subsequent cuts, furthermore it has been found to affect the fatigue behavior of the machined component, and to threat its fatigue life as well [18].

\subsection{Microstructural alterations}

In metal cutting, most of the plastic work is converted to heat, the material therefore is not only subjected to mechanical loadings (high stress and strain), but to thermal impact simultaneously, and under some circumstances even to chemical energies as well. These effects are responsible for the microstructural alterations in the material, such as plastic deformation as mentioned above, phase transformation and the formation of white layer $[55,56]$.

The white layer was first identified in steel wire ropes [57]. This layer has a very high resistance to etching and appears featureless under optical microscope. Three main mechanisms responsible for white layer generation have been suggested [58]:

- Rapid heating and quenching, giving rise to phase transformation;

- Surface reactions with environment;

- Plastic work which produces a homogeneous microstructure or a microstructure with very fine grains.

In turning of hardened steels, it has been shown that the quenching mechanism of rapid heating and cooling in which the surface material was transformed from austenitic to martensitic structure played the most importance role in white layer creation [59]. In turning of Inconel 718, the white layer formed at the machined surface was found to consist of nano-crystalline grains, which is predominantly ascribed to dynamic recrystallization and grain subdivision by severe plastic deformations [56]. The white layer is normally harder than the bulk material, but also it is brittle, therefore its formation might cause cracks to initiate in the material [60], and further affect the fatigue strength of the final product [61]. 


\subsection{Residual stresses}

Residual stresses are stresses that remain in materials after the original loading has been removed. They originate from elastic response to the inhomogeneous distribution of nonelastic strains as the consequence of the misfits either between different regions or between different phases [62]. The formation of residual stresses in machining processes is generally considered to be due to mainly plastic deformation in the sub-surface of the machined component and thermal impact at the surface [63]. Mechanically induced residual stresses could be either tensile or compressive, depending on the deformation that occurs at the tool/workpiece contact surface. If the compressive plastic deformation ahead of the tool tip as shown in Fig. 8 is lower than the tensile one behind it, the material in the surface layer consequently will experience an overall tensile plastic deformation, giving rise to compressive residual stresses, and vice versa. Thermally induced residual stresses, however, are usually tensile. In machining, the mechanically and thermally induced residual stresses always exist simultaneously where the relative significance varies from one process to another [64]. Phase transformation and dynamic recrystallization as the consequence of the thermal impact can also induce residual stresses owing to the non-uniform changes in the physical and mechanical properties of the workpiece material.

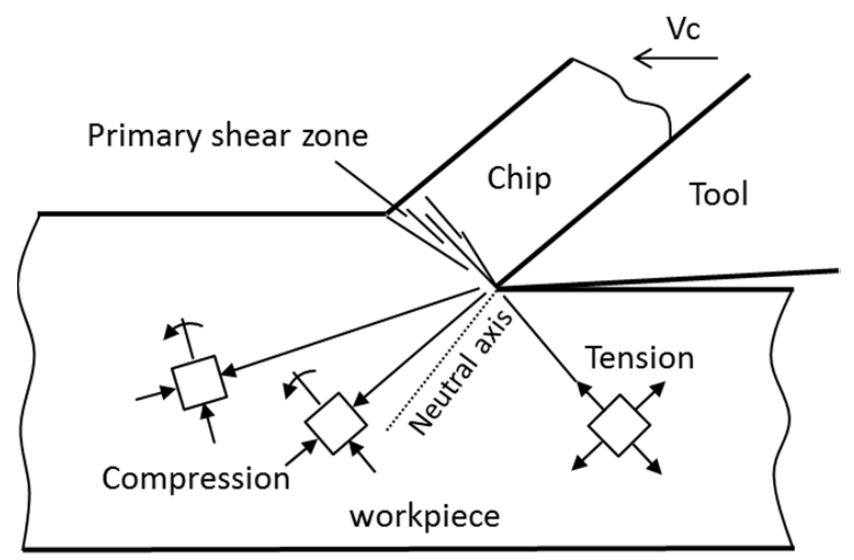

Fig. 8 the orthogonal cutting model and compression ahead of the tool tip

The generation of residual stresses during machining is governed by the workpiece material being machined as well as the cutting conditions and tool parameters used in the machining. Compressive residual stresses are generally beneficial when taking fatigue strength into consideration, while tensile residual stresses on the other hand should be avoided. When machining Inconel 718, however, it is mostly found that residual stresses 
are more tensile at the surface of the workpiece and they gradually become compressive as the depth increases [47, 65-66]. Another problem that the residual stresses produced by machining may cause is dimensional instability of the workpiece. The dimensional instability is basically a change in dimension with respect to time without any work being done on the part. This phenomenon brings problems in structural assembly, as it destroys the structural integrity. Inconel 718 has revealed dimensional instability after machining, and it is more prone to dimensional changes in comparison with either titanium alloy or mild steel $[67,68]$.

Service monitoring and failure analysis of dynamic components reveal that fatigue failures mostly initiate at the surface or in the near surface region, and the surface integrity again is recognized to be the primary factor that determines the susceptibility of the component to attacks and subsequent failures [69]. Thus, the driving force for advancing the knowledge of machining induced surface integrity is to enhance the reliability and durability of machined components/parts, especially for safety critical components such as gas turbine discs. 



\section{7}

\section{Experimental methods}

In this chapter, the experimental methods used in this project are presented. The broaching operation was conducted at Siemens Industrial Turbomachinery AB in Finspång, Sweden. All sample preparation, thermal exposure, microstructural studies and residual stress measurements were performed at Linköping University. Nano-indentation tests, however, were made at Lund University.

\subsection{Material}

Inconel 718 alloys used in this project was supplied as a forging $(200 \mathrm{~mm} \times 200 \mathrm{~mm} \times$ $50 \mathrm{~mm}$ ) via Siemens Industrial Turbomachinery by a material supplier. The chemical composition in wt. \% for the Inconel 718 is given in Table 1 . The forging was solution annealed by the material supplier at $970{ }^{\circ} \mathrm{C}$ for $3.5 \mathrm{~h}$, followed by ageing for $8 \mathrm{~h}$ at 720 ${ }^{\circ} \mathrm{C}$ and further for $8 \mathrm{~h}$ at $620{ }^{\circ} \mathrm{C}$.

Table 1 Chemical composition (wt. \%) of Inconel 718

\begin{tabular}{lr}
\hline $\mathrm{Ni}$ & 53.9 \\
$\mathrm{Cr}$ & 17.9 \\
$\mathrm{Nb}+\mathrm{Ta}$ & 5.5 \\
$\mathrm{Mo}$ & 2.9 \\
$\mathrm{Ti}$ & 1 \\
$\mathrm{Al}$ & 0.5 \\
$\mathrm{Co}$ & 0.2 \\
$\mathrm{C}$ & 0.25 \\
$\mathrm{Si}$ & 0.04 \\
$\mathrm{~B}$ & 0.004 \\
$\mathrm{Fe}$ & $\mathrm{Bal}$ \\
\hline
\end{tabular}




\subsection{Broaching}

Slots with fir-tree profile were machined on the edge of the forging by using linear surface broaching on a vertical broach machine at Siemens Industrial Turbomachinery. The broach used in this case is made of PM-T15 high speed steel (65 - 67 HRC) with semi-worn conditions, and the RPT for roughing, semi-finishing and finishing section is $0.066 \mathrm{~mm}, 0.054-0.038 \mathrm{~mm}$ and $0.013 \mathrm{~mm}$ respectively. The broaching was conducted at $12^{\circ}$ cutting angle, $3^{\circ}$ clearance angle with a fixed cutting speed of $3 \mathrm{~m} / \mathrm{min}$ under oil cooling. The chosen parameters are close to those used for machining fir-tree root fixings in production discs at Siemens Industrial Turbomachinary. The broached forging is presented in Fig. 9(a). Specimens were taken from the forging by wire-cut electric discharge machining (WEDM) at the workshop in Linköping University. The WEDM exposed the broached surface of the lower joint of the root fixings for subsequent studies as shown in Fig. 9(b).
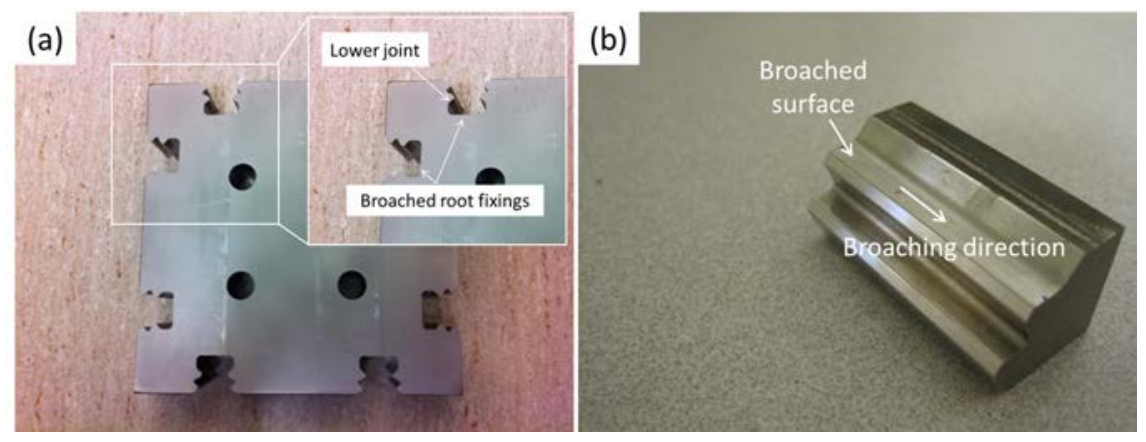

Fig. 9 (a) Inconel 718 forging with broached fir-tree root fixings at the edge; (b) Specimen taken from the forging to expose the broached surface of the lower joint of the root fixings

\subsection{Thermal exposure}

Gas turbine discs always operate at high temperatures, the disc material therefore is subjected to high thermal loads during service. To investigate the structural integrity of the broached specimens in terms of microstructure and residual stresses under high temperature conditions, thermal exposure was performed in a furnace in air. Three temperatures were chosen, $450{ }^{\circ} \mathrm{C}, 550{ }^{\circ} \mathrm{C}$ and $650{ }^{\circ} \mathrm{C}$. $450{ }^{\circ} \mathrm{C}$ and $550{ }^{\circ} \mathrm{C}$ are very close to the service temperature $\left(\sim 500{ }^{\circ} \mathrm{C}\right)$ for gas turbine discs made of Inconel 718 , while $650{ }^{\circ} \mathrm{C}$ is generally considered to be the temperature limitation for the applications of this alloy. In addition, the thermal exposure was conducted for different time intervals till 3000 hours. 


\subsection{Microscopy}

\subsubsection{Sample preparation}

To enable to observe the microstructure beneath the broached surface as well as the microstructural alterations after thermal exposure, a careful sample preparation was performed for microscopic studies. All specimens prepared for microstructural studies were firstly ground and then mechanically polished by using a Struer grinding and polishing machine. SiC grinding papers from \# 500 with a particle size of $30 \mu \mathrm{m}$ down to \# 4000 with a particle size of $5 \mu \mathrm{m}$ were used before mechanical polishing with diamond suspensions from $3 \mu \mathrm{m}$ to $1 / 4 \mu \mathrm{m}$ was conducted. Chemical polishing was performed as the last step to get good contrast microscopy images. After each step, specimens and holder were cleaned by using water and ethanol. Ultrasonic cleaning was performed as well to remove contaminations from the grinding paper and polishing agent.

\subsubsection{Scanning electron microscopy (SEM)}

Three SEM related techniques were used for the microstructural investigations: electron channeling imaging (ECCI), electron backscatter diffraction (EBSD) and energy dispersive spectroscopy (EDS).

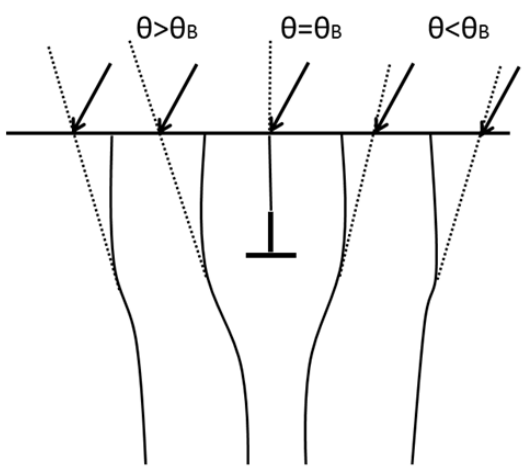

BSES

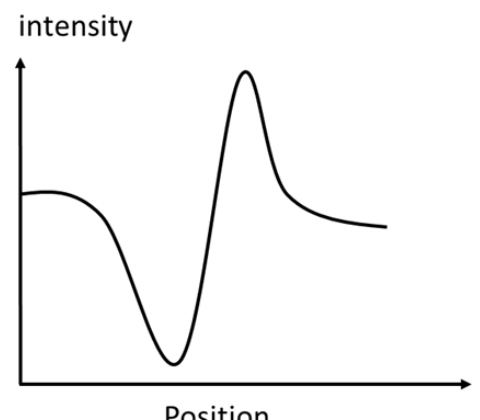

Fig. 10 Schematic diagram showing how the local distortion near a dislocation gives rise to an alteration of the BSE intensity allowing the dislocation to be imaged

In 1967, Coates reported the strong crystallographic orientation dependence of the intensity of primary backscattered electrons (BSEs) [70]. Immediately following this, Booker et al. [71] confirmed Coates' observations and put forward a theoretical interpretation of this phenomenon in which it states the BSEs intensity changes rapidly with orientations when the incident beam is close to the Bragg condition for a given set of 
lattice planes. In this paper, Booker et al. also suggested the basic idea of using the electron channeling phenomenon to image dislocations or other defects near the surface of a bulk specimen. When the incident beam is oriented at the Bragg positon $\left(\theta_{\mathrm{B}}\right)$ of a given set of crystal planes, the local distortion of the lattice planes where dislocations exist will provide a sufficient contrast in SEM images, as shown in Fig. 10. The ECCI technique has been successfully used to capture plastic deformation, twin structures and even dislocations in highly deformed materials [72-74]. Fig. 11 shows the shear deformation and the plastically deformed grain with multiple slip bands in broached Inconel 718, using the ECCI technique.
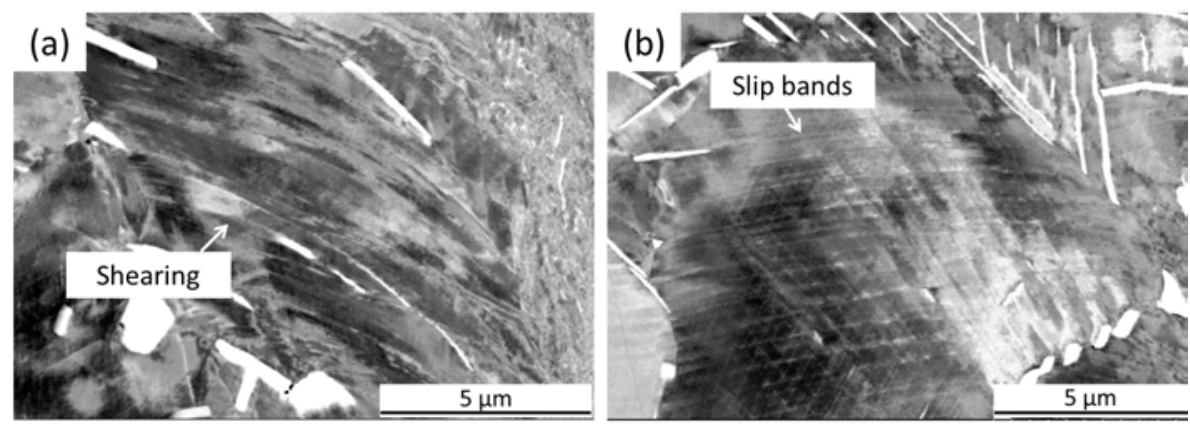

Fig. 11 ECCI images of (a) shearing deformation; (b) Plastically deformed grain in broached Inconel 718

EBSD is a microstructural-crystallographic technique that can be used to identify the crystal structure of a material, and to index its crystallographic orientation, by using Kikuchi patterns [75]. EBSD mapping provides an efficient approach to view plastic deformation at both macrostructural and microstructural levels by monitoring the change in the quality of Kikuchi patterns [76] and the change in intragranular crystal orientations $[77,78]$. EDS is an analytical technique for the element analysis or chemical composition characterization of a sample [79]. When combined with EBSD, it can be used to identify the precipitates formed in alloys [80].

All microstructural investigations were performed in a Hitachi SU-70 field emission gun (FEG)-scanning electron microscope (SEM) equipped with a 4-quadrant solid state BSE detector, an OXFORD EBSD detector and an energy-dispersive detector. The EBSD analysis, for example, crystal misorientations calculation, was done by using the HKL software CHANEL 5. 


\subsection{X-ray diffraction}

\subsubsection{Residual stress measurement by diffraction}

Residual stresses in a workpiece are commonly measured by either monitoring component distortions when deliberately removing material to allow the stresses to relax, or by diffraction methods. Laboratory x-ray diffraction, synchrotron (hard x-ray) diffraction and neutron diffraction as the most widely used diffraction methods for residual stress measurements are based on the same principle and they are complementary to each other [62, 81]. Laboratory x-rays can only be used for the measurement of surface residual stresses since most $x$-rays are absorbed after penetrating less than $100 \mu \mathrm{m}$ in materials owing to the electromagnetic interaction with orbiting electrons. In contrast, the weak interaction of the uncharged neutrons with electrons allows the neutron beam to penetrate even a few hundred millimeters into some light metals, the penetration depth approaches $\sim 200 \mathrm{~mm}$ in the case of $\mathrm{Al}$, for instance, with a result that bulk residual stresses can be measured. Synchrotron x-rays whose intensity can be as much as a million times more than laboratory x-rays now becomes available, providing over a thousand times more penetrating in metals. However, the disadvantages of the neutron and synchrotron diffraction are the high cost and the low lateral spatial resolution. In this project, laboratory x-ray diffraction was chosen for the residual stress measurements as for a machined component, residual stresses are generated mostly near the surface.

\subsubsection{Principle}

When measuring residual stresses by diffraction, elastic strain $\varepsilon$ is determined by changes in inter-planner spacing $\Delta d$ which is derived from the Bragg equation through a given incident wavelength $\lambda$ and the measured change in the Bragg scattering angle $\Delta \theta$

$\lambda=2 d \sin \theta$

giving

$\varepsilon=\frac{\Delta d}{d_{0}}=-\cot \theta \Delta \theta$

Equation 2

It is worth noting that an accurate measure of $d_{0}$, the stress free spacing of the measured lattice planes, is critical before the residual stress measurement. The strain results subsequently can be converted to stress by using a suitable stiffness value [82]. 
Equation 2 illustrates the basic principle for the diffraction methods used for residual stress measurements. In practice, to make a stress measurement by x-ray diffraction, the sample coordinate system S and the laboratory coordinate L, as shown in Fig. 12, have to be introduced. The calculated strains and stresses are expressed in the sample coordinate system. The laboratory coordinate system $\mathrm{L}$ is fixed as that $\mathrm{L}_{3}$ defined by the two angles $\phi$ and $\psi$ is in the direction of the bisectrix between the incident and measured diffraction beam, thus normal to the family of planes (hkl) whose inter-planer spacing is measured by diffraction. $\mathrm{L}_{2}$ is in the plane defined by $\mathrm{S}_{1}$ and $\mathrm{S}_{2}$ and makes the angle $\phi$ with $\mathrm{S}_{2}$.

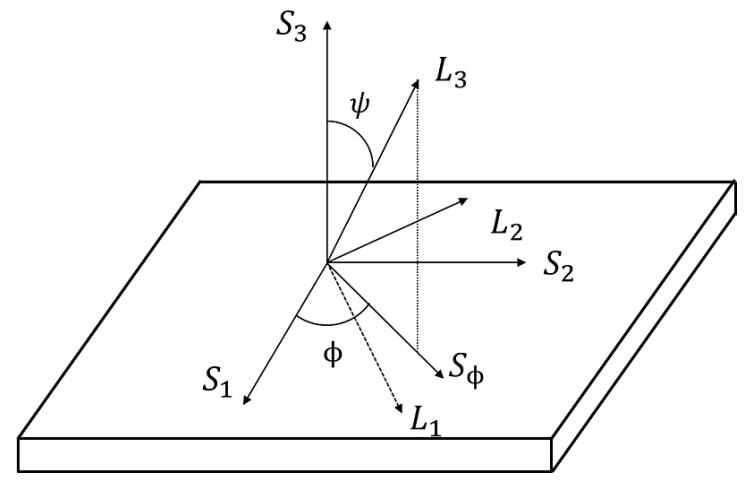

Fig. 12 Coordinate systems used in residual stress measurement with $x$-ray diffraction

The measured strain $\varepsilon_{\phi \psi}$ in the $\mathrm{L}_{3}$ can be expressed in terms of $\varepsilon_{\mathrm{ij}}$ in the specimen coordinate system by the equation [83]:

$$
\begin{aligned}
\varepsilon_{\phi \psi}= & \varepsilon_{11} \cos ^{2} \phi \sin ^{2} \psi+\varepsilon_{12} \sin 2 \phi \sin ^{2} \psi \\
& +\varepsilon_{22} \sin ^{2} \phi \sin ^{2} \psi+\varepsilon_{33} \cos ^{2} \psi \\
& +\varepsilon_{13} \cos \phi \sin 2 \psi+\varepsilon_{23} \sin \phi \sin 2 \psi
\end{aligned}
$$

Equation 3

In order to calculate the strains and stresses in the sample, at least six independent measurements of strain in different directions $\varepsilon_{\phi \psi}$ are required. The relationship between strain and stress in an isotropic material is given by Hook's law:

$\varepsilon_{\mathrm{ij}}=\frac{1+v}{E} \sigma_{\phi \Psi}-\frac{v}{E} \delta_{\mathrm{ij}}\left(\sigma_{11}+\sigma_{22}+\sigma_{33}\right)$

Equation 4

Where $\delta_{\mathrm{ij}}$ is Kronecke' delta, E and $v$ are Young's modulus of elasticity and Poisson's ratio, respectively. Combining Equation 3 and Equation 4 yields 


$$
\begin{aligned}
\frac{d_{\phi \psi}-d_{0}}{d_{0}}= & \frac{1+v}{E}\left\{\sigma_{11} \cos ^{2} \phi+\sigma_{12} \sin 2 \phi+\sigma_{22} \sin ^{2} \phi-\sigma_{33}\right\} \sin ^{2} \psi \\
& +\frac{1+v}{E} \sigma_{33}-\frac{v}{E}\left\{\sigma_{11}+\sigma_{22}+\sigma_{33}\right\} \\
& +\frac{1+v}{E}\left\{\sigma_{13} \cos \phi+\sigma_{23} \sin \phi\right\} \sin 2 \psi
\end{aligned}
$$

Equation 5

\subsubsection{The " $\sin ^{2} \psi$ " method}

The most classical method to calculate residual stresses in a specimen from x-ray diffraction data is the $\sin ^{2} \psi$-method. If the target material is isotropic, and the stress state in the irradiated surface is biaxial $\left(\sigma_{33}=0\right.$, and shear components $\sigma_{13}, \sigma_{23}=0$ as well), Equation 5 becomes

$\frac{d_{\phi \psi}-d_{0}}{d_{0}}=\frac{1+v}{E} \sigma_{\phi} \sin ^{2} \psi-\frac{v}{E}\left\{\sigma_{11}+\sigma_{22}\right\}$

Equation 6

Where $\sigma_{\phi}$ is the stress component in the $S_{\phi}$ direction as shown in Fig. 12, given by

$\sigma_{\phi}=\sigma_{11} \cos ^{2} \phi+\sigma_{12} \sin 2 \phi+\sigma_{22} \sin ^{2} \phi$

Equation 7

Due to the shallow penetration depth of x-rays, it is reasonable to make these assumptions to simplify the calculations. According to Equation 6, when $d_{\phi \psi}$ is plotted as a function of $\sin ^{2} \psi$, a linear relationship can be predicted and the stress in the $S_{\phi}$ direction is then obtained from the slop of a least-square line fitted to the diffraction data measured at various $\psi$ with a fixed $\phi$, if the elastic constants E, $v$ and the stress free plane spacing $d_{0}$ have been known. This method is known as the " $\sin ^{2} \psi$ " technique [84]. One way to get the $d_{0}$ is to make a x-ray diffraction on the stress free powder of the material to be measured, but in most residual stress measurements, the lattice spacing measured at $\psi=$ $0^{\circ}$ is used to substitute $d_{0}$.

When $\sigma_{13}$ and $\sigma_{23}$ are zero, a linear variation of $d$ vs. $\sin ^{2} \psi$ has been predicted. However, when either or both of these shear components are non-zero, the linear relationship is lost because the term "sin $2 \psi$ " in Equation 5 becomes non-zero, and it causes a split in the $d$ vs. $\sin ^{2} \psi$ data, termed “ $\psi$-splitting” [83]. The " $\psi$-splitting” eventually leads to a large experimental uncertainty for the residual stress measurements.

The residual stress measurements in this thesis were made by X-ray diffraction using a four-circle Seifert $\mathrm{X}$-ray diffractometer equipped with a linear position sensitive detector. $\mathrm{Cr}-\mathrm{K}_{\alpha}$ radiation was chosen, giving a high diffraction peak at $2 \theta \sim 128^{\circ}$ for the $\{220\}$ family of lattice planes of the nickel-based matrix. Peaks were measured at nine $\psi$-angles 
between $\psi=+45^{\circ}$ and $\psi=-45^{\circ}$. Pseudo Voigt function was used for peak fitting in order to determine diffraction peak positions and Full Widths at Half Maximum (FWHM). Residual stresses were calculated based on the " $\sin ^{2} \psi$ " method with an X-ray elastic constant of $4.65 \times 10^{-6} \mathrm{MPa}^{-1}$ which is commonly used for $\{220\}$ diffraction planes of the nickel-based matrix of Inconel 718. The in-depth profiles were obtained by electrolytical polishing with Struers LectroPol-5 on an area of $11 \mathrm{~mm} \times 5 \mathrm{~mm}$ with a depth varying between $5 \mu \mathrm{m}$ and $50 \mu \mathrm{m}$.

\subsection{Nano-indentation}

Nano-indentation is a type of indentation hardness tests. It was developed in the early 1970s [85, 86], and has become an increasingly popular mean of testing mechanical properties of small volumes of a material, particularly in the area of thin films [87-89]. In nano-indentation, different from micro-hardness measurements, small loads and tip sizes are used, resulting in an indent with only a few square micrometers or even nanometers. Atomic force microscopy [90] or scanning electron microscopy [91] can be utilized to image the residual indent after unloading, but the determination of nano-indentation hardness usually uses the load-displacement curve [92]. An indenter with a geometry known to high precision is employed. When the indenter is pressed into specimen till a given maximum load, a record of the penetration depth is made synchronously. The area of the indent then can be calculated by using the known geometry of the indenter, and a load-displacement curve is created from which hardness and Young's modulus of the specimen can be analyzed based on the Oliver and Pharr method [93].

It has been shown that the nano-indentation technique is frequently engaged in characterizing the machining induced work-hardened layer beneath the machined surface [94-96]. In addition, nano-indentation also provides an alternative approach to estimate other surface integrity issues which have an influence on the micro-mechanical behavior of the machined alloy, such as residual stresses [97] and phase transformations [98]

The nano-indentation tests in this thesis were performed at Lund University in order to characterize the machining induced work-hardening beneath the broached surface, and to investigate the effect of thermal exposure on the sub-surface mechanical behavior of broached Inconel 718 as well. 


\section{Summary of appended papers}

\section{Paper I}

\section{Structural integrity of broached Inconel 718 subjected to thermal exposure}

The purpose of this study is to characterize the surface integrity of broached Inconel 718, and then to investigate the microstructural degradation as well as the residual stress relief beneath the broached surface when the specimen is subjected to thermal exposure. A broaching operation was performed on a forged Inconel 718 coupon using very similar cutting conditions as that used in gas turbine industries for machining fir-tree root fixings. Thermal exposure was conducted in air at $450{ }^{\circ} \mathrm{C}, 550{ }^{\circ} \mathrm{C}$ and $650{ }^{\circ} \mathrm{C}$ for three different time intervals, $30 \mathrm{~h}, 300 \mathrm{~h}$ and $3000 \mathrm{~h}$ respectively followed by air cooling.

Surface defects, severe plastic deformation and generation of high tensile residual stresses were identified to be the main damages induced by the broaching operation. The surface defects comprise broaching marks, surface cavities and surface smearing. The latter two types of defects are associated with the cracking of carbides at the broached surface. The machining-induced plastic deformation was found to be responsible for the microstructural instability observed in the broached specimen at high temperatures. Recrystallization took place in the surface layer, giving a recrystallized area without $\gamma^{\prime \prime}$ at the broached surface. Meanwhile, $\alpha$-Cr precipitated at relatively lower temperature and also within much shorter exposure time beneath the broached surface in comparison with that in the bulk. The surface tensile residual stresses were completely removed when recrystallization occurred in the surface layer, whereas the tensile layer in the sub-surface region exhibited a high resistance to stress relaxation at high temperatures. 


\section{Paper II}

\section{Effect of thermal exposure on microstructure and nano-hardness of broached Inconel 718}

This study is aimed to investigate machining induced work-hardening in broached Inconel 718 and the further hardness variations of the broached specimen when subjected to thermal exposure. Microstructural studies using the ECCI and EBSD technique and nano-indentation were performed on three specimens. One was kept in the as-broached condition and the other two specimens were thermally exposed at $550{ }^{\circ} \mathrm{C}$ for $300 \mathrm{~h}$ and at $650{ }^{\circ} \mathrm{C}$ for $300 \mathrm{~h}$ respectively followed by air cooling.

The nano-hardness of the material after being broached was found to be higher on the surface than that through the depth of the specimen. A work-hardened layer with a thickness of $\sim 50 \mu \mathrm{m}$ was formed beneath the broached surface in response to the machining induced plastic deformation. It was shown that the thermal exposure at the two applied temperatures led to an increase in nano-hardness both in the work-hardened layer and in the bulk material with similar amplitudes. Coarsening of the main strengthening phase $\gamma^{\prime \prime}$ is responsible for the higher nano-hardness after thermal exposure. Inconel 718 is an alloy with low stacking fault energy where the presence of solute atoms and precipitates also reduce the mobility of dislocations, thereby hindering the occurrence of thermal recovery. The heat treatment therefore had little effect on softening the workhardened layer formed beneath the broached surface.

\section{Paper III}

\section{Analysis of thermal effect on the residual stresses of broached Inconel 718}

This study focuses on the residual stress state in broached Inconel 718 and its relief when the broached specimen is subjected to thermal exposure. This knowledge can later be used for analyzing the initiation and propagation of fatigue cracks in broached Inconel 718 especially in the case of high temperature fatigue since residual stresses strongly affect the fatigue behavior of machined components by changing the mean stress and stress amplitude. The thermal exposure was conducted at $550{ }^{\circ} \mathrm{C}$ which is close to the operating temperature normally designed for the turbine disc made of Inconel 718.

The broaching operation has been found to produce high tensile residual stresses at the machined surface. In the sub-surface region, a layer with tensile residual stresses was formed, followed by a layer several times thicker with compressive residual stresses. It has also been found that complete relaxation of the surface tensile residual stresses can be 
obtained when early stage recrystallization took place in the surface layer, whereas the fully recrystallization occurred in the surface layer after longer thermal exposure converted the surface residual stresses into compression. At the meantime, the long-term thermal exposure effectively reduced the tensile residual stresses generated in the subsurface region as well.

\section{Paper IV}

\section{Damage analysis of a retired gas turbine disc}

In this study, an analysis was performed in a retired gas turbine disc of Inconel 718 to investigate the service damages that could occur in gas turbine discs and to understand correlations between the damages and the machining induced changes in surface integrity. The region being studied was restricted to the broached fir-tree root fixings of the retired disc. The disc has been in operation for $11749 \mathrm{~h}$ and 194 starts and the service temperature was $\sim 500{ }^{\circ} \mathrm{C}$.

The retired disc experienced oxidation attack and microstructural degradation as the consequence of the high operating temperature in service. Recrystallization and $\alpha$-Cr precipitation were found in the disc material where intensive pre-plastic deformation has be induced by the broaching manufacturing and the shot peening surface treatment. This microstructural degradation is in agreement with the machining-induced microstructural instability observed previously in broached Inconel 718 after thermal exposure. Fretting fatigue occurred at the contact surface of the blade and disc pressure face. The fretting fatigue caused internal oxidation in the disc alloy, thereby exacerbating the oxidation attack on the contact surface. The existence of the machined surface layer with highly deformed structure was found to be negative for preventing the occurrence of fretting fatigue damages since cracking of the surface layer was observed locally in the disc alloy. 



\section{9 \\ Conclusions}

The main purpose of a turbine disc is to locate and hold the rotating turbine blades through the fir-tree root fixings produced by broaching, while the surface quality/integrity of these broached fixings to a great extent determines the endurance and reliability of the disc when taking fatigue into account. The research presented in this licentiate thesis concerns the surface integrity of broached Inconel 718 with a focus on surface damages, microstructural alterations beneath the broached surface and the generation of residual stresses. Nickel-based superalloy Inconel 718 was chosen since it is extensively used as the turbine disc material in aerospace and power generation industries. The broaching operation in this research was performed by using very similar cutting conditions as that used in gas turbine industries for machining fir-tree root fixings.

The microstructural studies shows that the main defects on the broached surface comprise broaching marks, surface cavities and surface smearing. The latter two surface defects have been found to be associated with carbide cracking. Beneath the broached surface, a work-hardened layer is formed as the consequence of the severe plastic deformation produced by broaching. For residual stresses, the broaching operation produces a high level of surface tensile residual stresses that gives rise to a potential risk in terms of crack initiation from the fatigue point of view. In the sub-surface region, a layer with tensile residual stresses is formed, followed by a layer several times thicker with compressive residual stresses.

Turbine discs normally operate at high temperatures. Thermal exposure therefore was conducted at $450{ }^{\circ} \mathrm{C}, 550{ }^{\circ} \mathrm{C}$ and $650{ }^{\circ} \mathrm{C}$ for different time intervals up to $3000 \mathrm{~h}$. The broaching operation causes instability in microstructure beneath the machined surface when subjected to thermal exposure: recrystallization takes place in the surface layer and $\alpha$-Cr precipitates in the vicinity of the $\delta$ phase. It has been found that the broaching induced plastic deformation accelerated the formation of the $\alpha$-Cr precipitates. For residual stresses, the recrystallization gives rise to a complete relaxation of the surface 
tensile residual stresses after short time thermal exposure, whereas the tensile residual stresses in the sub-surface region show a relatively high resistance to thermal relaxation.

A damage analysis was also performed on a retired gas turbine disc made of Inconel 718 which has been in operation for $11749 \mathrm{~h}$ and 194 starts. Recrystallization and $\alpha$-Cr precipitation as the two main signs of the machining-induced microstructural instability observed previously in the broached Inconel 718 after thermal exposure are also identified in the retired dis. The existence of the machined surface layer whose plasticity has been exhausted has been found to be negative for preventing the occurrence of fretting fatigue damages at the contact surface of the blade and disc pressure face since cracking of the surface layer is observed locally in the disc alloy.

In the work completed so far in this project much attention has been given to evaluate the damages to the surface integrity of Inconel 718 induced by broaching, and also to investigate the stability of the broached sample under high temperature conditions. Future work will focus predominantly on fatigue properties of broached Inconel 718 both at room temperature and elevated temperatures. Already in plan is bending fatigue testing of the as-broached alloy and also broached specimens with subsequent thermal exposures. Surface integrity in machining of other superalloys and its influence on the mechanical properties particularly fatigue resistance is also another topic for future work. 


\section{Bibliography}

[1] R.C. Reed, The Superalloys: Fundamentals and Applications, Cambridge University Press, 2006.

[2] L. Witek, Failure analysis of turbine disc of an aero engine, Eng. Failure Anal. 13 (2006) 9-17.

[3] S.R. Lampman, ASM Handbook: Volume 19, Fatigue and Fracture, ASM International. (1996).

[4] Z. Mazur, A. Luna-Ramirez, J. Juárez-Islas, A. Campos-Amezcua, Failure analysis of a gas turbine blade made of Inconel 738LC alloy, Eng. Failure Anal. 12 (2005) 474-486.

[5] J. Chang, Y. Yun, C. Choi, J. Kim, Failure analysis of gas turbine buckets, Eng. Failure Anal. 10 (2003) 559-567.

[6] M. Khajavi, M. Shariat, Failure of first stage gas turbine blades, Eng. Failure Anal. 11 (2004) 589-597.

[7] E. Poursaeidi, M. Aieneravaie, M. Mohammadi, Failure analysis of a second stage blade in a gas turbine engine, Eng. Failure Anal. 15 (2008) 1111-1129.

[8] C.D. Lykins, S. Mall, V.K. Jain, Combined experimental-numerical investigation of fretting fatigue crack initiation, Int. J. Fatigue. 23 (2001) 703-711.

[9] Kocanda. S, Fatigue Failure of Metals, Sihthoff and Noordhoff International Publishers, 1978.

[10] D.W. Hoeppner, Fretting fatigue case studies of engineering components, Tribol. Int. 39 (2006) 1271-1276.

[11] W. Betteridge, S. Shaw, Development of superalloys, Mater. Sci. Technol. 3 (1987) 682-694.

[12] J.M. Oblak, D.F. Paulonis, D.S. Duvall, Coherency strengthening in Ni-base alloys hardened by $\mathrm{DO}_{22}$ gamma double prime precipitates, Metall. Trans. 5 (1974) 143-153.

[13] D. Paulonis, J. Oblak, D. Duvall, Precipitation in nickel-base alloy 718, Trans. Quart. ASM. 62 (1969) 611-622.

[14] J. Brooks, P. Bridges, Metallurgical stability of Inconel alloy 718, Superalloys. 88 (1988) 33-42. 
[15] D.R. Muzyka, G. Maniar, Effects of solution treating temperature and microstructure on the properties of hot-rolled 718 alloy, Metals Eng. Quart. 9 (1969) 2337.

[16] A. Koul, P. Au, N. Bellinger, R. Thamburaj, W. Wallace, J. Immarigeon, S. Reichman, D. Duhl, G. Maurer, S. Antolovich, Superalloys 1988, Metallurgical Society. (1988) 3.

[17] J.F. Radavich, Metallography of alloy 718, JOM Journal of the Minerals, Metals and Materials Society. 40 (1988) 42-43.

[18] T. Connolley, P. Reed, M. Starink, Short crack initiation and growth at $600^{\circ} \mathrm{C}$ in notched specimens of Inconel718, Mater. Sci. Eng. A. 340 (2003) 139-154.

[19] J.R. Davis, Nickel, Cobalt, and Their Alloys, ASM international, 2000.

[20] A. Oradei-Basile, J.F. Radavich, A current TTT diagram for wrought alloy 718, Superalloys. 718 (1991) 325-335.

[21] P. Wright, Machinability of Metals, Pergamon Press, Encyclopedia of Materials Science and Engineering. 4 (1986).

[22] E. Ezugwu, Z. Wang, A. Machado, The machinability of nickel-based alloys: a review, J. Mater. Process. Technol. 86 (1998) 1-16.

[23] I.A. Choudhury, M.A. El-Baradie, Machinability of nickel-base super alloys: a general review, J. Mater. Process. Technol. 77 (1998) 278-284.

[24] R. Arunachalam, M.A. Mannan, Machinability of nickel-based high temperature alloys, Mach. Sci. Technol. 4 (2000) 127-168.

[25] E.O. Ezugwu, Key improvements in the machining of difficult-to-cut aerospace superalloys, Int. J. Mach. Tools Manuf. 45 (2005) 1353-1367.

[26] D.G. Thakur, B. Ramamoorthy, L. Vijayaraghavan, Machinability investigation of Inconel 718 in high-speed turning, Int. J. Adv. Manuf . Technol. 45 (2009) 421-429.

[27] M.C. Shaw, Metal Cutting Principles, Clarendon press Oxford, 1984.

[28] R. Recht, Catastrophic thermoplastic shear, J. Appl. Mech. 31 (1964) 189-193.

[29] S. Timothy, The structure of adiabatic shear bands in metals: a critical review, Acta Metall. 35 (1987) 301-306.

[30] J. Lorentzon, N. Järvstråt, B. Josefson, Modelling chip formation of alloy 718, J. Mater. Process. Technol. 209 (2009) 4645-4653.

[31] G. Dong, H. Zhaopeng, H. Rongdi, C. Yanli, J. Muguthu, Study of cutting deformation in machining nickel-based alloy Inconel 718, Int. J. Mach. Tools Manuf. 51 (2011) 520-527.

[32] S. Mo, D. Axinte, T. Hyde, N. Gindy, An example of selection of the cutting conditions in broaching of heat-resistant alloys based on cutting forces, surface roughness and tool wear, J. Mater. Process. Technol. 160 (2005) 382-389.

[33] F. Klocke, P. Vogtel, S. Gierlings, D. Lung, D. Veselovac, Broaching of Inconel 718 with cemented carbide, Production Eng. 7 (2013) 593-600. 
[34] D.A. Axinte, N. Gindy, Tool condition monitoring in broaching, Wear. 254 (2003) 370-382.

[35] N. Suchkov, V. Latyshev, Effects of coolant on surface finish in broaching, Machines Tooling. 44 (1973) 49-50.

[36] D. Axinte, An experimental analysis of damped coupled vibrations in broaching, Int. J. Mach. Tools Manuf. 47 (2007) 2182-2188.

[37] V. Sajeev, L. Vijayaraghavan, U. Rao, Effect of tool-work deflections on the shape of a broached hole, Int. J. Mech. Eng. Edu. 28 (2000) 88-92.

[38] M. Field, J. Kahles, The surface integrity of machined-and ground high-strength steels, DMIC Report. 210 (1964) 54-77.

[39] M. Field, J.F. Kahles, J. Cammett, Review of measuring methods for surface integrity, CIRP. 21 (1972) 219-238.

[40] D. Novovic, R.C. Dewes, D.K. Aspinwall, W. Voice, P. Bowen, The effect of machined topography and integrity on fatigue life, Int. J. Mach. Tools Manuf. 44 (2004) $125-134$.

[41] Koster. W, Effect of residual stress on fatigue of structural alloys, Proceedings of the Third International Conference, ASM International, Indianapolis, Indiana, USA. (1991) 1-9.

[42] A. Sharman, J. Hughes, K. Ridgway, Workpiece surface integrity and tool life issues when turning Inconel $718^{\mathrm{TM}}$ nickel based superalloy, Mach. Sci. Technol. 8 (2004) 399414.

[43] A. Mantle, D. Aspinwall, Surface integrity of a high speed milled gamma titanium aluminide, J. Mater. Process. Technol. 118 (2001) 143-150.

[44] S. Joshi, S.P. Vizhian, B. Sridhar, K. Jayaram, Parametric study of machining effect on residual stress and surface roughness of nickel base super alloy UDIMET 720, Adv. Mater. Res. 47 (2008) 13-16.

[45] E. Ezugwu, J. Bonney, D. Fadare, W. Sales, Machining of nickel-base, Inconel 718, alloy with ceramic tools under finishing conditions with various coolant supply pressures, J. Mater. Process. Technol. 162 (2005) 609-614.

[46] A. Ginting, M. Nouari, Surface integrity of dry machined titanium alloys, Int. J. Mach. Tools Manuf. 49 (2009) 325-332.

[47] D. Dudzinski, A. Devillez, A. Moufki, D. Larrouquere, V. Zerrouki, J. Vigneau, A review of developments towards dry and high speed machining of Inconel 718 alloy, Int. J. Mach. Tools Manuf. 44 (2004) 439-456.

[48] D. Ulutan, T. Ozel, Machining induced surface integrity in titanium and nickel alloys: A review, Int. J. Mach. Tools Manuf. 51 (2011) 250-280.

[49] R. Pawade, S.S. Joshi, P. Brahmankar, M. Rahman, An investigation of cutting forces and surface damage in high-speed turning of Inconel 718, J. Mater. Process. Technol. 192 (2007) 139-146. 
[50] A. Sadat, M. Reddy, Surface integrity of inconel-718 nickel-base superalloy using controlled and natural contact length tools. Part I: Lubricated, Exp. Mech. 32 (1992) 282288.

[51] A. Sadat, M. Reddy, Surface integrity of inconel-718 nickel-base superalloy using controlled and natural contact length tools. Part II: Unlubricated, Exp. Mech. 33 (1993) 343-348.

[52] E. Ezugwu, Z. Wang, C. Okeke, Tool life and surface integrity when machining Inconel 718 with PVD-and CVD-coated tools, Tribol. Trans. 42 (1999) 353-360.

[53] C. Che-Haron, A. Jawaid, The effect of machining on surface integrity of titanium alloy Ti-6\% Al-4\% V, J. Mater. Process. Technol. 166 (2005) 188-192.

[54] R. Pawade, S.S. Joshi, P. Brahmankar, Effect of machining parameters and cutting edge geometry on surface integrity of high-speed turned Inconel 718, Int. J. Mach. Tools Manuf. 48 (2008) 15-28.

[55] X. Yang, C. Richard Liu, Machining titanium and its alloys, Mach. Sci. Technol. 3 (1999) 107-139.

[56] V. Bushlya, J. Zhou, F. Lenrick, P. Avdovic, J. Ståhl, Characterization of White Layer Generated when Turning Aged Inconel 718, Procedia Engineering. 19 (2011) 6066.

[57] J. Stead, Micro-metallography and its practical applications, Journal of Western Scottish Iron and Steel Institute. 19 (1912) 169-204.

[58] B. Griffiths, Mechanisms of white layer generation with reference to machining and deformation processes, J. Tribol. 109 (1987) 525-530.

[59] X. Sauvage, J. Le Breton, A. Guillet, A. Meyer, J. Teillet, Phase transformations in surface layers of machined steels investigated by X-ray diffraction and Mössbauer spectrometry, Mater. Sci. Eng. A. 362 (2003) 181-186.

[60] B. Zhang, W. Shen, Y. Liu, X. Tang, Y. Wang, Microstructures of surface white layer and internal white adiabatic shear band, Wear. 211 (1997) 164-168.

[61] D.W. Schwach, Y. Guo, A fundamental study on the impact of surface integrity by hard turning on rolling contact fatigue, Int. J. Fatigue. 28 (2006) 1838-1844.

[62] P. Withers, H. Bhadeshia, Residual stress. Part 2-Nature and origins, Mater. Sci. Technol. 17 (2001) 366-375.

[63] K. Jacobus, R. DeVor, S. Kapoor, Machining-induced residual stress: experimentation and modeling, J. Manuf. Sci. Eng. 122 (2000) 20-31.

[64] E. Brinksmeier, J. Cammett, W. König, P. Leskovar, J. Peters, H. Tönshoff, Residual stresses-measurement and causes in machining processes, CIRP Annals-Manufacturing Technology. 31 (1982) 491-510.

[65] A. Sharman, J. Hughes, K. Ridgway, An analysis of the residual stresses generated in Inconel 718 ${ }^{\mathrm{TM}}$ when turning, J. Mater. Process. Technol. 173 (2006) 359-367.

[66] C. Schlauer, R.L. Peng, M. Odén, Residual stresses in a nickel-based superalloy introduced by turning, Mater. Sci. Forum.404 (2002) 173-178. 
[67] B. Subhas, R. Bhat, K. Ramachandra, H. Balakrishna, Simultaneous optimization of machining parameters for dimensional instability control in aero gas turbine components made of Inconel 718 alloy, J. Manuf. Sci. Eng. 122 (2000) 586-590.

[68] B. Subhas, R. Bhat, K. Ramachandra, H. Balakrishna, Dimensional instability studies in machining of Inconel 718 nickel based superalloy as applied to aerogas turbine components, J. Eng. Gas Turb. Power. 122 (2000) 55-61.

[69] M. Field, J.F. Kahles, Review of Surface Integrity of Machined Components, Defense Technical Information Center., 1971.

[70] D. Coates, Kikuchi-like reflection patterns obtained with the scanning electron microscope, Philosophical Magazine. 16 (1967) 1179-1184.

[71] G. Booker, A. Shaw, M. Whelan, P. Hirsch, Some comments on the interpretation of the 'Kikuchi-like reflection patterns' observed by scanning electron microscopy, Philosophical Magazine. 16 (1967) 1185-1191.

[72] J.J. Moverare, S. Johansson, R.C. Reed, Deformation and damage mechanisms during thermal-mechanical fatigue of a single-crystal superalloy, Acta Mater. 57 (2009) 2266-2276.

[73] I. Gutierrez-Urrutia, S. Zaefferer, D. Raabe, Electron channeling contrast imaging of twins and dislocations in twinning-induced plasticity steels under controlled diffraction conditions in a scanning electron microscope, Scr. Mater. 61 (2009) 737-740.

[74] J. Talonen, H. Hänninen, Formation of shear bands and strain-induced martensite during plastic deformation of metastable austenitic stainless steels, Acta Mater. 55 (2007) 6108-6118.

[75] A.J. Schwartz, M. Kumar, B.L. Adams, D.P. Field, Electron Backscatter Diffraction in Materials Science, Springer, 2009.

[76] A. Wilkinson, D. Dingley, Quantitative deformation studies using electron back scatter patterns, Acta Metal. Mater. 39 (1991) 3047-3055.

[77] R. Ørsund, J. Hjelen, E. Nes, Local lattice curvature and deformation heterogeneities in heavily deformed aluminium, Scr. Metall. 23 (1989) 1193-1197.

[78] J.M. Zhou, V. Bushlya, R.L. Peng, J.E. Stahl, Identification of Subsurface Deformation in Machining of Inconel 718, Appl. Mech. Mater. 117 (2012) 1681-1688.

[79] J.I. Goldstein, D.E. Newbury, P. Echlin, D.C. Joy, C. Fiori, E. Lifshin, Scanning Electron Microscopy and X-Ray Microanalysis. A Text for Biologists, Materials Scientists, and Geologists. Plenum Publishing Corporation, 1981.

[80] S. Schlegel, S. Hopkins, E. Young, J. Cole, T. Lillo, M. Frary, Precipitate redistribution during creep of alloy 617, Metall. Mater. Trans. A. 40 (2009) 2812-2823.

[81] P. Withers, H. Bhadeshia, Residual stress. Part 1-measurement techniques, Mater. Sci. Technol. 17 (2001) 355-365.

[82] A. Krawitz, R. Winholtz, C. Weisbrook, Relation of elastic strain distributions determined by diffraction to corresponding stress distributions, Mater. Sci. Eng. A. 206 (1996) 176-182. 
[83] I.C. Noyan, J.B. Cohen, Residual stress-measurement by diffraction and interpretation, (1986).

[84] P.S. Prevey, X-ray diffraction residual stress techniques, ASM International, ASM Handbook. 10 (1986) 380-392.

[85] D. Newey, M. Wilkins, H. Pollock, An ultra-low-load penetration hardness tester, J. Phys. E: Sci. Instrum. 15 (1982) 119-122.

[86] J. Pethicai, R. Hutchings, W. Oliver, Hardness measurement at penetration depths as small as $20 \mathrm{~nm}$, Philos. Mag. A. 48 (1983) 593-606.

[87] R. Saha, W.D. Nix, Effects of the substrate on the determination of thin film mechanical properties by nanoindentation, Acta Mater. 50 (2002) 23-38.

[88] G. Pharr, W. Oliver, Measurement of thin film mechanical properties using nanoindentation, MRS Bull. 17 (1992) 28-33.

[89] D. Li, Y. Chung, M. Wong, W.D. Sproul, Nano - indentation studies of ultrahigh strength carbon nitride thin films, J. Appl. Phys. 74 (1993) 219-223.

[90] B. Bhushan, V.N. Koinkar, Nanoindentation hardness measurements using atomic force microscopy, Appl. Phys. Lett. 64 (1994) 1653-1655.

[91] R. Rabe, J. Breguet, P. Schwaller, S. Stauss, F. Haug, J. Patscheider, J. Michler, Observation of fracture and plastic deformation during indentation and scratching inside the scanning electron microscope, Thin Solid Films. 469 (2004) 206-213.

[92] D. Lucca, K. Herrmann, M. Klopfstein, Nanoindentation: Measuring methods and applications, CIRP Ann. Manuf. Technol. 59 (2010) 803-819.

[93] W.C. Oliver, G.M. Pharr, An improved technique for determining hardness and elastic modulus using load and displacement sensing indentation experiments, J. Mater. Res. 7 (1992) 1564-1583.

[94] R. M'Saoubi, T. Larsson, J. Outeiro, Y. Guo, S. Suslov, C. Saldana, S. Chandrasekar, Surface integrity analysis of machined Inconel 718 over multiple length scales, CIRP Ann. Manuf. Technol. 61 (2012) 99-102.

[95] J. Zhou, V. Bushlya, P. Avdovic, E. Ståhl Jan, Study of surface quality in high speed turning of Inconel 718 with uncoated and coated CBN tools, Int. J. Adv. Manuf. Technol. 58 (2012) 141-151.

[96] N. Ahmed, A. Mitrofanov, V. Babitsky, V. Silberschmidt, Analysis of material response to ultrasonic vibration loading in turning Inconel 718, Mater. Sci. Eng. A. 424 (2006) 318-325.

[97] S. Suresh, A. Giannakopoulos, A new method for estimating residual stresses by instrumented sharp indentation, Acta Mater. 46 (1998) 5755-5767.

[98] A. Warren, Y. Guo, M. Weaver, The influence of machining induced residual stress and phase transformation on the measurement of subsurface mechanical behavior using nanoindentation, Surf. Coat. Technol. 200 (2006) 3459-3467. 


\section{Part II}

\section{Papers Included}





\section{Papers Included}

The articles associated with this thesis have been removed for copyright reasons. For more details about these see:

http://urn.kb.se/resolve?urn=urn:nbn:se:liu:diva- 111062 